\title{
Influences of Flow Attack Angles and Flow Directions on Heat Transfer Rate, Pressure Loss, and Thermal Performance in Heat Exchanger Tube with V-Wavy Surface
}

\author{
Amnart Boonloi ${ }_{(D)}^{1}$ and Withada Jedsadaratanachai ${ }^{2}{ }^{2}$ \\ ${ }^{1}$ Department of Mechanical Engineering Technology, College of Industrial Technology, \\ King Mongkut's University of Technology North Bangkok, Bangkok 10800, Thailand \\ ${ }^{2}$ Department of Mechanical Engineering, Faculty of Engineering, King Mongkut's Institute of Technology Ladkrabang, \\ Bangkok 10520, Thailand \\ Correspondence should be addressed to Withada Jedsadaratanachai; kjwithad@kmitl.ac.th
}

Received 10 January 2018; Accepted 4 October 2018; Published 1 November 2018

Academic Editor: Dimitrios E. Manolakos

Copyright (C) 2018 Amnart Boonloi and Withada Jedsadaratanachai. This is an open access article distributed under the Creative Commons Attribution License, which permits unrestricted use, distribution, and reproduction in any medium, provided the original work is properly cited.

\begin{abstract}
Numerical investigations on flow and heat transfer characteristics in the heat exchanger tube with the V-wavy surface are presented. The finite volume method with the SIMPLE algorithm is selected to solve the present problem. The effects of flow attack angles $\left(\alpha=15^{\circ}, 20^{\circ}, 25^{\circ}, 30^{\circ}, 35^{\circ}, 40^{\circ}, 45^{\circ}, 50^{\circ}, 55^{\circ}\right.$, and $\left.60^{\circ}\right)$ and flow directions (V-tip pointing downstream known as " $\mathrm{V}$ Downstream" and V-tip pointing upstream known as "V-Upstream") for the V-wavy surface on flow and heat transfer patterns are considered for both laminar and turbulent regions. The laminar regime is studied in the range $\operatorname{Re}=100-1200$, while the turbulent region is investigated in the range $\mathrm{Re}=3000-10,000$. The mechanisms on flow and heat transfer in the test section are reported. The numerical results reveal that the V-wavy surface changes the flow structure in the test section. The vortex flow is produced by the $\mathrm{V}$-wavy surface. The vortex flow disturbs the thermal boundary layer on the heat transfer surface that is the reason for heat transfer and thermal performance enhancements. The optimum flow attack angles of the V-wavy surface for laminar and turbulent regimes are concluded.
\end{abstract}

\section{Introduction}

The developments of the heat exchangers to enhance heat transfer rate and thermal performance have been found in many industries such as chemical industry, automotive industry, and refrigerant system. The augmentations of the heat transfer rate and thermal performance in the heat exchangers can help to conserve the energy and operation cost of the system. The methods to enhance heat transfer rate in the system are divided into two types: active and passive techniques. The active technique requires the additional power such as vibration to increase heat transfer rate of the heating system. The use of the active technique must consider the economics for the process between the additional power and the increment of the thermal performance. The passive technique is the installation of the vortex generator or turbulator into the heating system to generate the vortex flow and to disturb the thermal boundary layer on the heat transfer surface.

Many researchers had analyzed the augmentation of the heat transfer rate in the heat exchanger by using turbulators. The investigations on flow configuration and heat transfer characteristics in the tube/channel heat exchanger are done on both experimental and numerical studies. For example, Chen et al. [1] numerically and experimentally investigated the flow and heat transfer of an impingement jet array with V-ribs on the target and impingement plates. The three different cases V-ribs on both the impingement and target plates, V-ribs placed on the impingement plate, and V-ribs placed on the target plate were compared for 
$\operatorname{Re}=15,000-35,000$. They reported that the highest Nusselt number ratio is around 1.16 for the $\mathrm{V}$-rib placed on the impingement plate and on both plates. Jin et al. [2] presented the thermohydraulic performance of a solar air heater installed with staggered multiple $\mathrm{V}$-shaped ribs on the absorber plate. They concluded that the staggered arrangement gives higher Nusselt number and thermal performance than the inline arrangement around $26 \%$ and $18 \%$, respectively. They also showed that the maximum thermal performance is around 2.43. Deo et al. [3] studied the heat transfer, pressure loss, and thermal performance in a rectangular duct placed with multigap $\mathrm{V}$-down ribs combined with staggered ribs on one wall. The influences of pitch-toheight ratio, rib height-to-hydraulic diameter ratio, and flow attack angle on flow and heat transfer were considered for $\operatorname{Re}=4000=12,000$. They summarized that the maximum augmentations on the Nusselt number and thermohydraulic performance were around 3.34 and 2.45 times, respectively. Kumar and Kim [4] reported the effects of the discrete multi$\mathrm{V}$-rib with the staggered rib in a solar air channel on heat transfer and thermal performance with the numerical method. They found that the overall thermal performance of the discrete multi-V-rib with a staggered rib shape is higher than the other rib shapes around 6\%. Maithani and Saini [5] experimentally investigated the enhancement of heat transfer rate in a solar air heater duct with the turbulence promoter. The V-ribs with symmetry gaps were selected to augment heat transfer rate and thermal performance. The influences of gap number, relative gap width, relative roughness pitch, angle of attack, and relative roughness height on heat transfer and pressure loss were considered for $\operatorname{Re}=4000-18,000$. They reported that the maximum Nusselt number and friction factor are around 3.6 and 3.67 times above the smooth duct, respectively. Kumar and Kim [6] numerically studied the heat transfer and flow mechanisms in an air duct with various $\mathrm{V}$-pattern ribs. They concluded that the best thermal performance is found in the case of the $\mathrm{V}$-pattern rib with groove roughness shapes. Fang et al. [7] investigated the turbulent flow in a square channel with $\mathrm{V}$-shaped ribs placed on one wall. The flow attack angles $30^{\circ}, 45^{\circ}, 60^{\circ}$, and $90^{\circ}$, for the V-shaped rib, were compared. Promthaisong et al. [8] numerically examined the fluid flow and heat transfer characteristic in a square channel heat exchanger with discrete broken V-ribs. They claimed that the discrete broken V-ribs can induce the longitudinal vortex flow which disturbs the thermal boundary layer on the heat transfer surface which is the reason for heat transfer augmentation. Jin et al. [9] numerically studied the heat transfer and flow behavior in a solar air heater channel with multi-V-shaped ribs on the absorber plate. They found that the optimum thermal performance is around 1.93. They also presented that the multi-V-shaped ribs help a better fluid mixing in the tested duct. Abraham and Vedula [10] presented the heat transfer and pressure loss in a square cross-sectional converging channel with $\mathrm{V}$-shaped and $\mathrm{W}$-shaped ribs for $\mathrm{Re}=$ 5000-35,000. Ravi and Saini [11] displayed the convective heat transfer in a solar air heater duct with discrete multi-Vshaped and staggered ribs on both sides of the absorber plate. The effects of relative staggered rib pitch, relative staggered rib size, and relative roughness width on heat transfer and pressure loss in the test section were investigated for $\mathrm{Re}=2000-20,000$. They found that the maximum Nusselt number and friction factor are around 4.52 and 3.13 times higher than the smooth duct, respectively.

The wavy surface is always selected to help to improve the heat transfer rate and thermal performance of the fin-andtube heat exchanger [12-18]. The wavy surface helps a better fluid mixing and increases the vortex strength of the flow that causes for heat transfer and thermal performance developments in the heat exchanger. Boonloi and Jedsadaratanachai $[19,20]$ reported the influences of the $\mathrm{V}$-wavy plate in a square channel heat exchanger on thermohydraulic performance. They claimed that the insertion of the $\mathrm{V}$-wavy plate can increase the heat transfer rate and thermal performance with moderate pressure loss penalty. Jedsadaratanachai and Boonloi [21] presented the inclined and $\mathrm{V}$-wavy plated in a circular tube heating system for laminar regime, $\mathrm{Re}=100-1200$. They found that the $\mathrm{V}$-Upstream wavy surface performs the highest TEF around 2.4 at $\mathrm{Re}=$ 2000. Jedsadaratanachai and Boonloi [22] numerically investigated the effects of wavy height and wavy thickness for the $\mathrm{V}$-wavy plate in a round tube heat exchanger on heat transfer rate, friction loss, and thermal performance. They concluded that the optimum wavy height and wavy thickness are around $0.10 \mathrm{D}-0.15 \mathrm{D}$ and $0.15 \mathrm{D}-0.20 \mathrm{D}$, respectively.

As per the literature reviews above, it is found that the $\mathrm{V}$-shaped turbulator gives high thermal efficiency, while the wavy surface is the turbulator that can be easily manufactured for the industrial system. In the present investigation, the concept of the V-shaped turbulator is combined with the wavy surface called "V-wavy surface". The V-wavy surface is inserted in the middle of the circular tube heat exchanger to enhance heat transfer rate and thermal performance. The influences of the flow attack angles and arrangements for the $\mathrm{V}$-wavy surface in the heating tube on heat transfer and flow behaviors are considered for both laminar and turbulent flow regimes. The laminar flow is presented for $\mathrm{Re}=$ 100-1200, while the turbulent flow regime is performed for $\operatorname{Re}=3000-10,000$. The $\mathrm{V}$-wavy surface may give high thermal performance and heat transfer rate similarly as the $\mathrm{V}$-shaped turbulators. Moreover, the production of the $\mathrm{V}$-wavy surface and installation in the heating system are easier than the $\mathrm{V}$-shaped rib or baffle.

\section{Physical Model}

The circular tube heat exchanger inserted with the V-wavy surface is depicted as Figure 1. The tube diameter, $D$, is set around $0.05 \mathrm{~m}$. The length periodic module of the circular tube equipped with the $\mathrm{V}$-wavy surface is created around $D$. The influences of the flow attack angles $\left(\alpha=15^{\circ}, 20^{\circ}, 25^{\circ}, 30^{\circ}\right.$, $35^{\circ}, 40^{\circ}, 45^{\circ}, 50^{\circ}, 55^{\circ}$, and $\left.60^{\circ}\right)$ and wavy surface arrangements (V-Downstream and V-Upstream) on heat transfer and pressure loss are considered for both laminar $(\mathrm{Re}=100-$ $1200)$ and turbulent $(\mathrm{Re}=3000-10,000)$ regimes. The square profile $(0.2 \mathrm{D} \times 0.2 \mathrm{D})$ of the wavy surface is set for all investigated cases. 


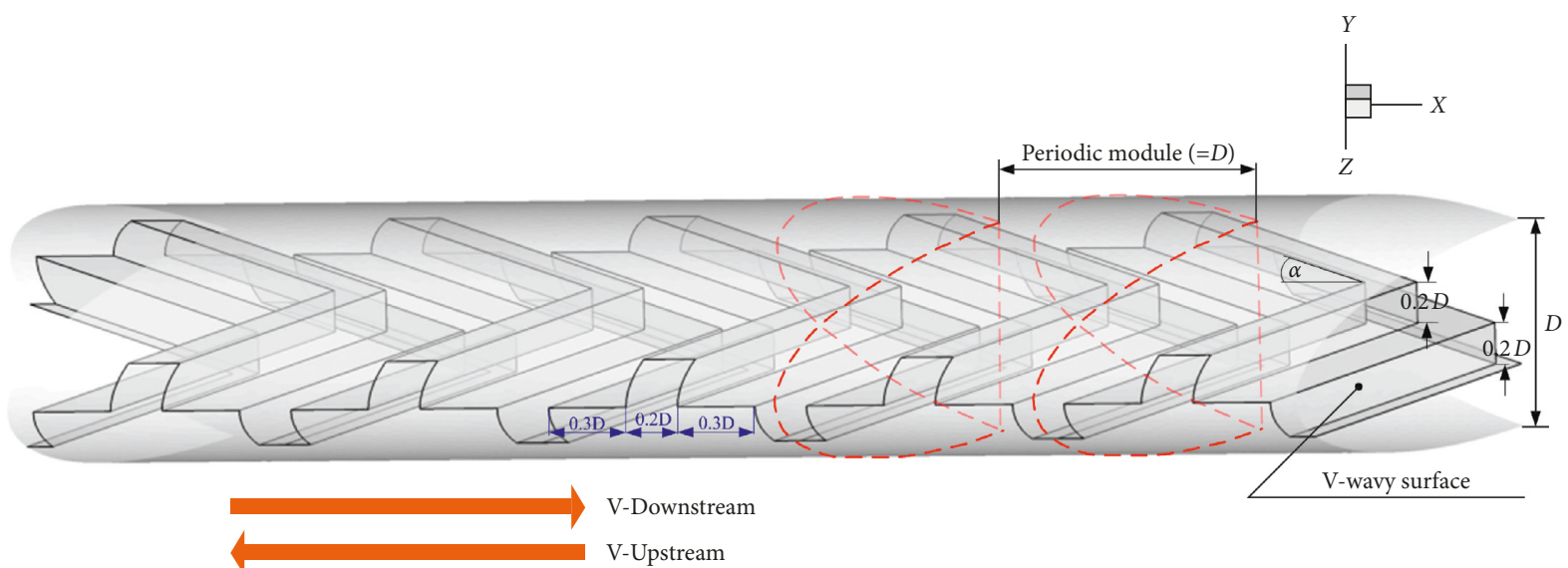

(a)

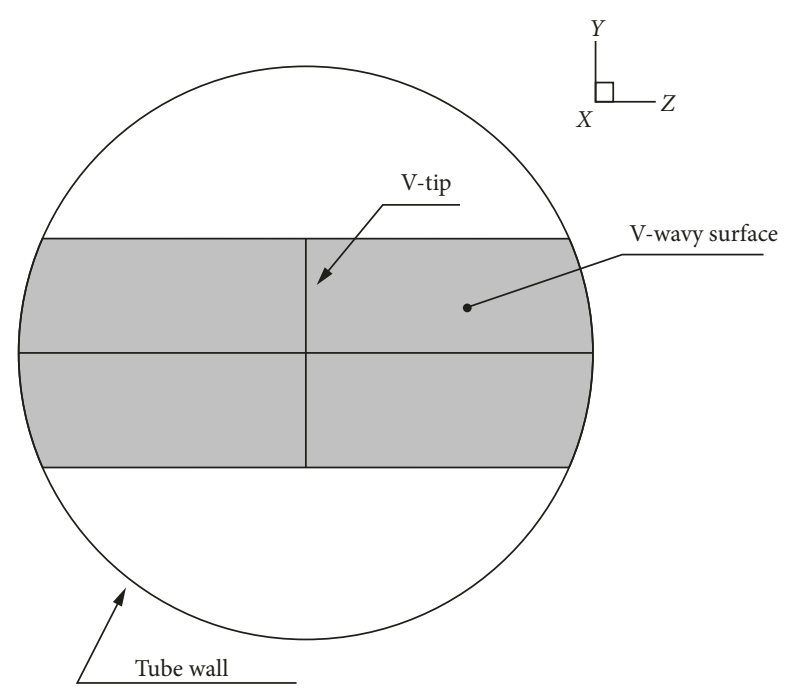

(b)

Figure 1: (a) Physical model of the heat exchanger tube inserted with the V-wavy surface and (b) tube geometry in the transverse plane.

\section{Mathematical Foundation and Numerical Method}

The mathematical model of the circular tube heat exchanger inserted with the $\mathrm{V}$-wavy surface is governed by the continuity, the Navier-Stokes equations, and the energy equation. For the laminar flow regime, the governing and energy equations are discretized by the power law and SOU schemes, respectively. All governing equations are discretized by the SOU numerical scheme for the turbulent flow regime. The present investigation is answered by the finite volume method with the SIMPLE algorithm. The solutions are considered to be converged when the normalized residual values are less than $10^{-5}$ for all variables, but less than $10^{-9}$ only for the energy equation.

The realizable $k-\varepsilon$ turbulent model for the turbulent flow region is written as

$$
\begin{aligned}
\frac{\partial}{\partial t}(\rho k)+\frac{\partial}{\partial x_{j}}\left(\rho k u_{j}\right)= & \frac{\partial}{\partial x_{j}}\left[\left(\mu+\frac{\mu_{\mathrm{t}}}{\sigma_{k}}\right) \frac{\partial k}{\partial x_{j}}\right] \\
& +G_{k}+G_{b}-\rho \varepsilon+Y_{M}+S_{k}
\end{aligned}
$$

and

$$
\begin{aligned}
\frac{\partial}{\partial t}(\rho \varepsilon)+\frac{\partial}{\partial x_{j}}\left(\rho \varepsilon u_{j}\right)= & \frac{\partial}{\partial x_{j}}\left[\left(\mu+\frac{\mu_{\mathrm{t}}}{\sigma_{\varepsilon}}\right) \frac{\partial \varepsilon}{\partial x_{j}}\right]+\rho C_{1} S \varepsilon \\
& +\rho C_{2} \frac{\varepsilon^{2}}{k+\sqrt{v \varepsilon}}+C_{1 \varepsilon} \frac{\varepsilon}{k} C_{3 \varepsilon} G_{b}+S_{\varepsilon}
\end{aligned}
$$

where 


$$
\begin{aligned}
C_{1} & =\max \left[0.43, \frac{\eta}{\eta+5}\right], \\
\eta & =S \frac{k}{\mathcal{E}} \\
S & =\sqrt{2 S_{i j} S_{i j}},
\end{aligned}
$$

and the constant values are as follows:

$$
\begin{aligned}
C_{1 \varepsilon} & =1.44, \\
C_{2} & =1.9, \\
\sigma_{k} & =1.0, \\
\sigma_{\varepsilon} & =1.2 .
\end{aligned}
$$

The important parameters are Reynolds number, friction factor, local Nusselt number, average Nusselt number, and thermal enhancement factor.

The Reynolds number is calculated as

$$
\operatorname{Re}=\frac{\rho \bar{u} D}{\mu} .
$$

The friction factor, $f$, is measured by pressure drop, $\Delta p$, across the periodic module, $L$ :

$$
f=\frac{(\Delta p / L) D}{(1 / 2) \rho \bar{u}^{2}} .
$$

The local heat transfer is written as

$$
\mathrm{Nu}_{x}=\frac{h_{x} D}{k} \text {. }
$$

The average Nusselt number can be obtained by

$$
\mathrm{Nu}=\frac{1}{A} \int \mathrm{Nu}_{x} \partial A
$$

The insertion of the V-wavy surface increases both heat transfer rate and pressure loss in the heat exchanger. Therefore, the thermal performance in terms of the thermal enhancement factor (TEF) is presented to analyze the advantage of the $\mathrm{V}$-wavy surface.

The thermal enhancement factor is calculated by the increases on both heat transfer and friction factor at a similar pumping power condition:

$$
\mathrm{TEF}=\left.\frac{h}{h_{0}}\right|_{\mathrm{pp}}=\left.\frac{\mathrm{Nu}}{\mathrm{Nu}_{0}}\right|_{\mathrm{pp}}=\left(\frac{\left(\mathrm{Nu} / \mathrm{Nu}_{0}\right)}{\left(f / f_{0}\right)}\right)^{1 / 3} .
$$

$\mathrm{Nu}_{0}$ and $f_{0}$ are the Nusselt number and friction factor for the smooth circular tube, respectively.

\section{Boundary Condition and Assumption}

The assumptions for the present investigation are as follows:

(i) The flow and heat transfer are steady in three dimensions

(ii) The test fluid is air at $300 \mathrm{~K}$ with the Prandtl number around 0.707 (iii) The air is set as incompressible fluid on both laminar and turbulent flows

(iv) The thermal properties of the air assume to be constant at the average bulk mean temperature

(v) The forced convective heat transfer is considered, while the natural convection and radiation are ignored

(vi) The body force and viscous dissipation are uncounted

The boundary conditions for the computational domain on both laminar and turbulent flows are concluded as Table 1.

\section{Numerical Validation}

The different number of grid cells 80000, 120000, 180000, 240000, and 360000 for the computational domain of the heat exchanger tube inserted with wavy $\mathrm{V}$-surface $\left(\alpha=30^{\circ}\right.$, $\mathrm{V}$-Downstream with $\mathrm{Re}=600$ for laminar and $\mathrm{Re}=6000$ for turbulent) are compared on both flow and heat transfer. It is found that the augmentation of the grid cell from 120000 to 180000 has no effect for the Nusselt number and friction factor values. Therefore, the grid around 120000 cells is created for all investigated cases when considered on both the time for solving the problem and the accuracy result.

The computational domains of the smooth circular tube with no wavy surface are validated on both flow and heat transfer. The verifications are done by comparing between the values from the present prediction and the values from the correlations. The numerical results reveal that the deviations on the Nusselt number are around \pm 0.03 and $\pm 5 \%$ for laminar flow and turbulent flow, respectively, and around $\pm 0.05 \%$ and $\pm 11 \%$ for the friction factor, respectively. The validations of the smooth circular tube for laminar and turbulent regimes are depicted as Figures 2 and 3 , respectively. As the preliminary test of the computational domain, it can be concluded that the present computational domain has enough reliability to predict flow and heat transfer in the heat exchanger tube equipped with the $\mathrm{V}$-wavy surface for laminar and turbulent regimes.

\section{Numerical Result}

The numerical results are divided into two parts: laminar and turbulent regimes. The flow configuration and heat transfer characteristic in the test section are presented. The performance evaluations for the tube heat exchanger equipped with the $\mathrm{V}$-wavy surface are also concluded.

\subsection{Laminar Flow}

6.1.1. Flow and Heat Transfer Configuration. The flow mechanisms in the heat exchanger tube equipped with the $\mathrm{V}$-wavy surface are reported in terms of $\lambda_{2}$ isosurface, tangential velocity vector in the transverse plane, and longitudinal vortex flow. Figures 4 (a) and 4(b) show the $\lambda_{2}$ isosurface in the heat exchanger tube equipped with the $\mathrm{V}$-wavy surface for $\mathrm{V}$-Downstream and $\mathrm{V}$-Upstream, respectively, at $\operatorname{Re}=600$ and $\alpha=30^{\circ}$. The $\lambda_{2}$ isosurface is an indicator to describe the core of the vortex flow in the test section. As shown in the figures, the vortex core is detected through the test tube for both arrangements. For the 
TABLE 1: Boundary condition for the computational domain of the heat exchanger tube equipped with the $\mathrm{V}$-wavy surface.

\begin{tabular}{lc}
\hline Zone & Boundary condition \\
\hline Inlet & Periodic \\
Outlet & Periodic \\
Tube wall & Constant temperature at $310 \mathrm{~K}$ and no slip wall \\
Wavy & condition \\
surface & Insulator and no slip wall condition \\
\hline
\end{tabular}

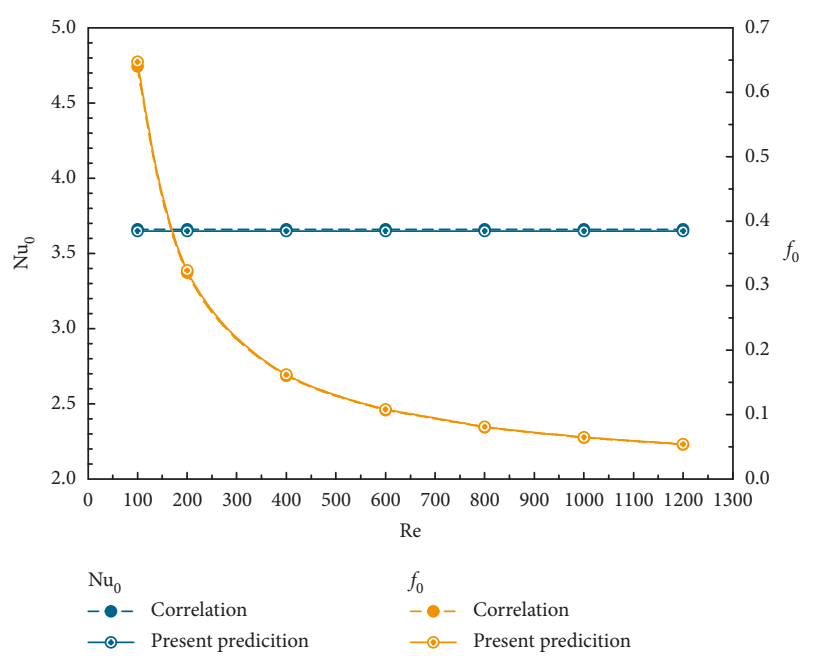

FIGURE 2: Validation of the smooth circular tube for the laminar flow.

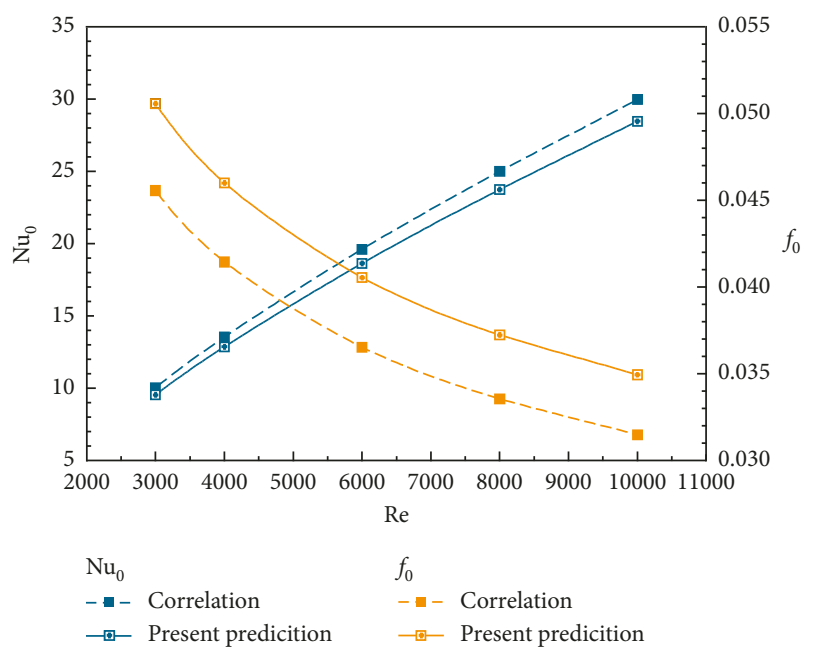

FIGURE 3: Validation of the smooth circular tube for the turbulent flow.

$\mathrm{V}$-Downstream, the vortex core appears on the $\mathrm{V}$-groove from sidewall to V-tip before flow across to the next module. For the V-Upstream, the flow slides on the V-groove from $\mathrm{V}$-tip to sidewall before flow across to the next module. The strength of the vortex flow depends on the flow attack angle, Reynolds number, and flow direction.
The tangential velocity vector in the transverse planes for the heat exchanger tube equipped with the V-wavy surface is presented as Figures 5(a) and 5(b), respectively, for $\mathrm{V}$-Downstream and V-Upstream at $\mathrm{Re}=600$ and $\alpha=30^{\circ}$. As shown in the figures, the vortex flow is found through the test section on both arrangements. The flow includes four main vortex cores. Considering the upper pair of the vortex flow in each plane, the counterrotating flow with commonflow-up is found in case of V-Downstream, while the $\mathrm{V}$-wavy surface gives the difference of the flow rotation. The difference of the flow structure leads to the change of the heat transfer behavior in the heat exchanger tube.

Figures 6(a) and 6(b) show the longitudinal vortex flow in the heat exchanger tube inserted with $\mathrm{V}$-Downstream and $\mathrm{V}$-Upstream of the $\mathrm{V}$-wavy surface, respectively, at $\mathrm{Re}=600$ and $\alpha=30^{\circ}$. As shown in the figures, it is indicated that the difference of the $\mathrm{V}$-wavy surface arrangement effects for the change of the flow structure. The $\mathrm{V}$-Downstream produces the impinging flow on the $\mathrm{V}$-groove from the sidewall to the $\mathrm{V}$-tip, while the V-Upstream performs the impinging flow on the $\mathrm{V}$-groove from the $\mathrm{V}$-tip to the sidewall.

The heat transfer behaviors in the heat exchanger tube inserted with the $\mathrm{V}$-wavy surface are reported in terms of temperature distributions in transverse planes and local Nusselt number distributions on the tube wall. The temperature distributions in transverse planes of the heat exchanger tube inserted with V-Downstream and V-Upstream wavy surfaces are illustrated as Figures $7(\mathrm{a})$ and $7(\mathrm{~b})$, respectively, for $\mathrm{V}$-downstream and V-Upstream at $\mathrm{Re}=600$ and $\alpha=30^{\circ}$. As shown in the figures, it is found that the $\mathrm{V}$-wavy surface changes the temperature distributions pattern for both arrangements. The better fluid mixing is detected when inserting the $\mathrm{V}$-wavy surface in the heat exchanger tube. The low temperature of the fluid (blue contour) distributes from the center of the plane, while the high temperature of the fluid (red contour) near the tube wall performs thinner. The thermal boundary layer disturbance on the heat transfer surface is also found. The better fluid mixing and thermal boundary layer disturbance are reasons for heat transfer rate and thermal performance enhancements. The different arrangement of the $\mathrm{V}$-wavy surface effects for the change of the thermal boundary layer.

Figures 8(a) and 8(b) displays the local Nusselt number distributions on the tube wall of the heat exchanger tube inserted with the $\mathrm{V}$-wavy surface for $\mathrm{V}$-Downstream and $\mathrm{V}$-Upstream, respectively, at $\operatorname{Re}=600$ and $\alpha=30^{\circ}$. The $\mathrm{V}$-Downstream gives the peak of the heat transfer surface at the upper-lower part of the tube, while the V-Upstream provides the highest heat transfer rate the left-right part of the tube.

6.1.2. Performance Assessment. In this part, the heat transfer rate, pressure loss, and thermal performance are concluded in term of Nusselt number $(\mathrm{Nu})$, friction factor $(f)$, and thermal enhancement factor (TEF), respectively. Figures 9(a) and 9(b) present the variations of the Nusselt number ratio $\left(\mathrm{Nu} / \mathrm{Nu}_{0}\right)$ with the Reynolds number for the 


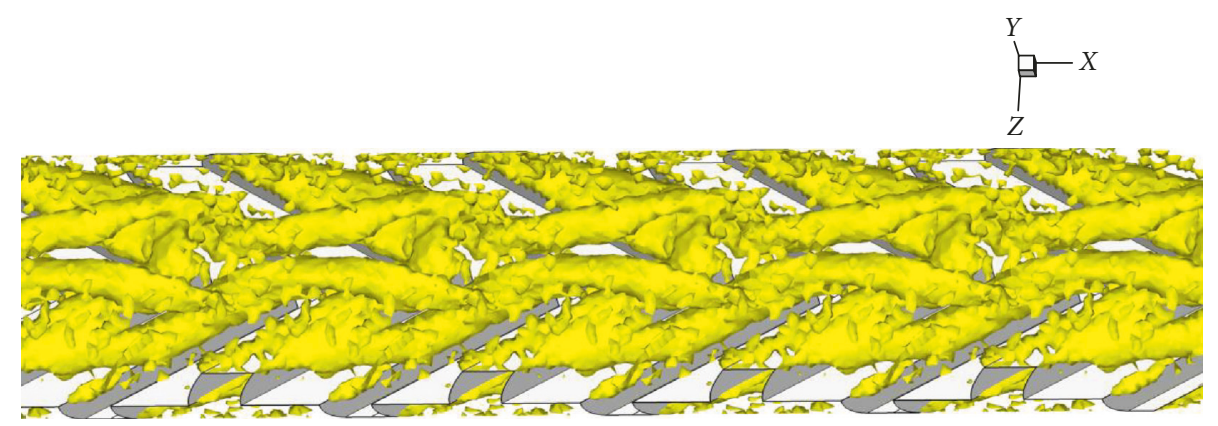

(a)

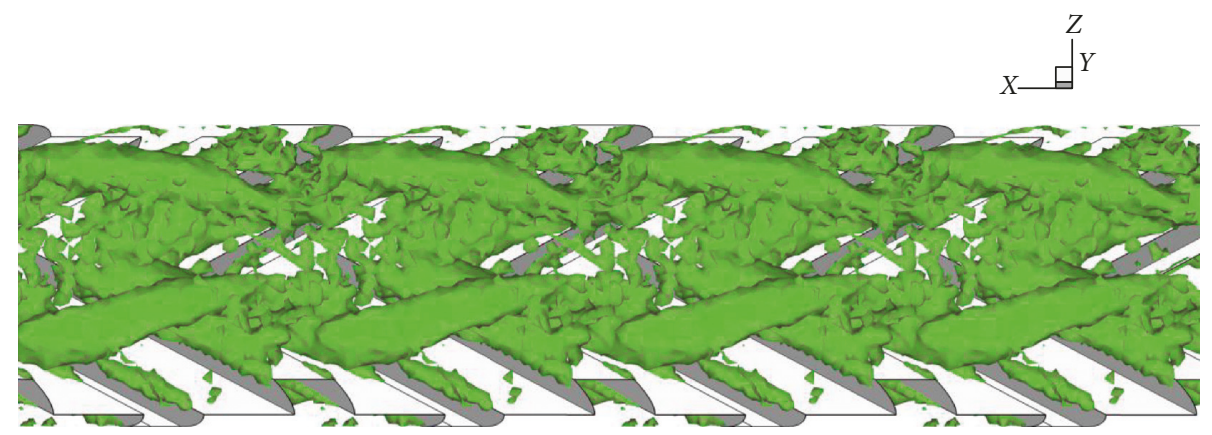

(b)

Figure 4: $\lambda_{2}$ isosurface of the heat exchanger tube inserted with the $V$-wavy surface at $\alpha=30^{\circ}$ and $\operatorname{Re}=600$ for (a) V-Downstream and (b) VUpstream.

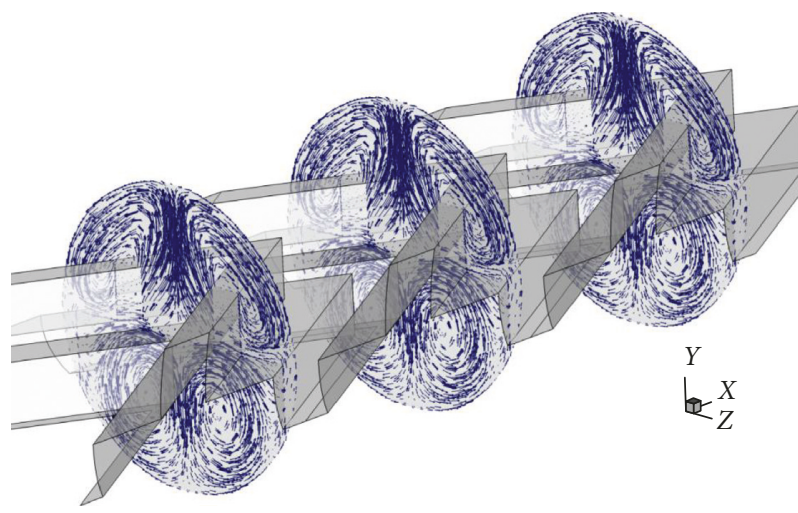

(a)

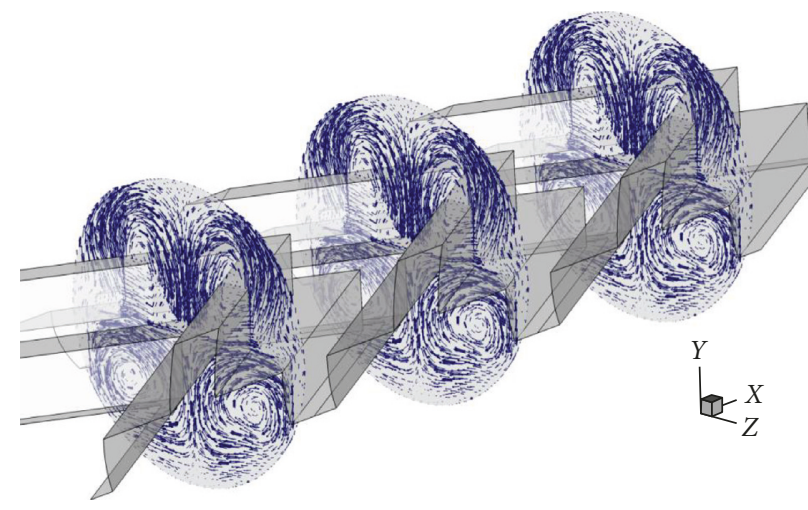

(b)

FIgURE 5: Tangential velocity vector in transverse planes of the heat exchanger tube inserted with the V-wavy surface at $\alpha=30^{\circ}$ and $\operatorname{Re}=600$ for (a) V-Downstream and (b) V-Upstream.

heat exchanger tube inserted with the V-Downstream and $\mathrm{V}$-Upstream wavy surfaces, respectively. In general, the $\mathrm{Nu} / \mathrm{Nu}_{0}$ increases when increasing the Reynolds number for both arrangements. The enhancement of the Reynolds number (augmentation of the fluid velocity) directly effects for the strength of the vortex flow. The disturbance of the thermal boundary layer on the heat transfer surface is clearly detected when enhancing the Reynolds number. $\mathrm{Re}=1200$ produces the highest heat transfer rate, while $\mathrm{Re}=100$ gives the opposite result. The present of the V-wavy surface in the heating tube gives greater heat transfer rate than the smooth circular tube $\left(\mathrm{Nu} / \mathrm{Nu}_{0}>1\right) . \mathrm{Nu} / \mathrm{Nu}_{0}$ is around $1.96-2.53$ and 6.07-11.15 for the V-Downstream wavy surface at $\mathrm{Re}=100$ and 1200 , respectively, while around $1.72-2.30$ and $7.23-$ 12.11, respectively, for the $\mathrm{V}$-Upstream wavy surface.

Figures 10(a) and 10(b) illustrate the relations of $f / f_{0}$ with the Reynolds number for the heat exchanger tube inserted with V-Downstream and V-Upstream wavy surfaces, respectively. Generally, $f / f_{0}$ increases when increasing the Reynolds number for all investigated cases. The peak of the friction factor value is detected at $\operatorname{Re}=1200$, while $\operatorname{Re}=100$ gives the reverse trend. The insertion of the $\mathrm{V}$-wavy surface 


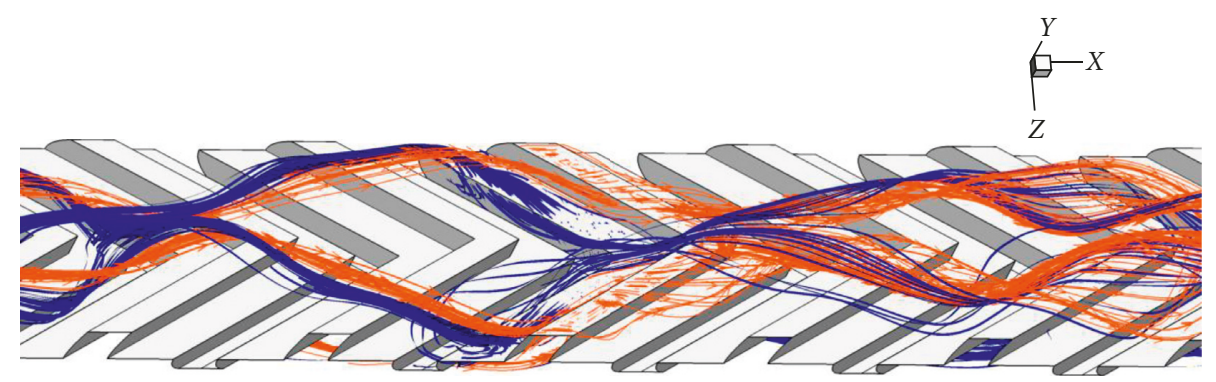

(a)

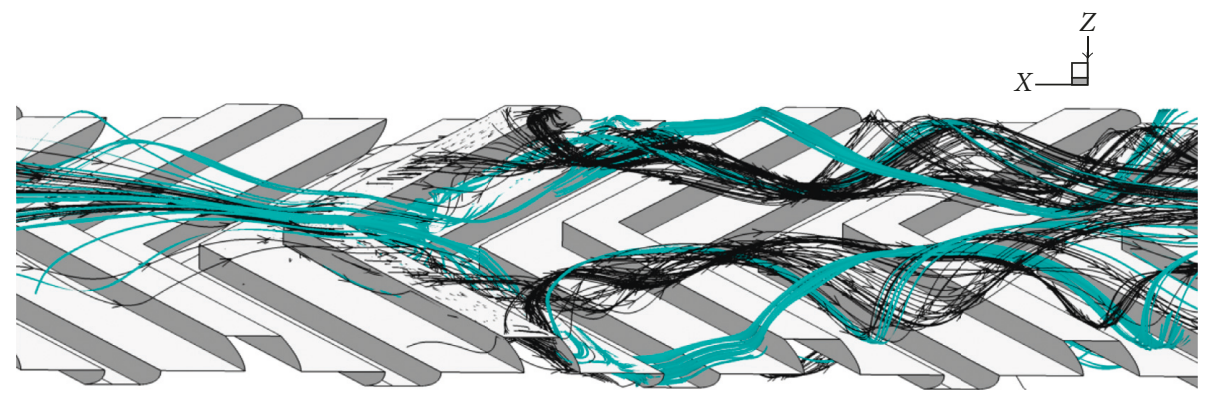

(b)

Figure 6: Longitudinal vortex flow of the heat exchanger tube inserted with the V-wavy surface at $\alpha=30^{\circ}$ and $\mathrm{Re}=600$ for (a) VDownstream and (b) V-Upstream.

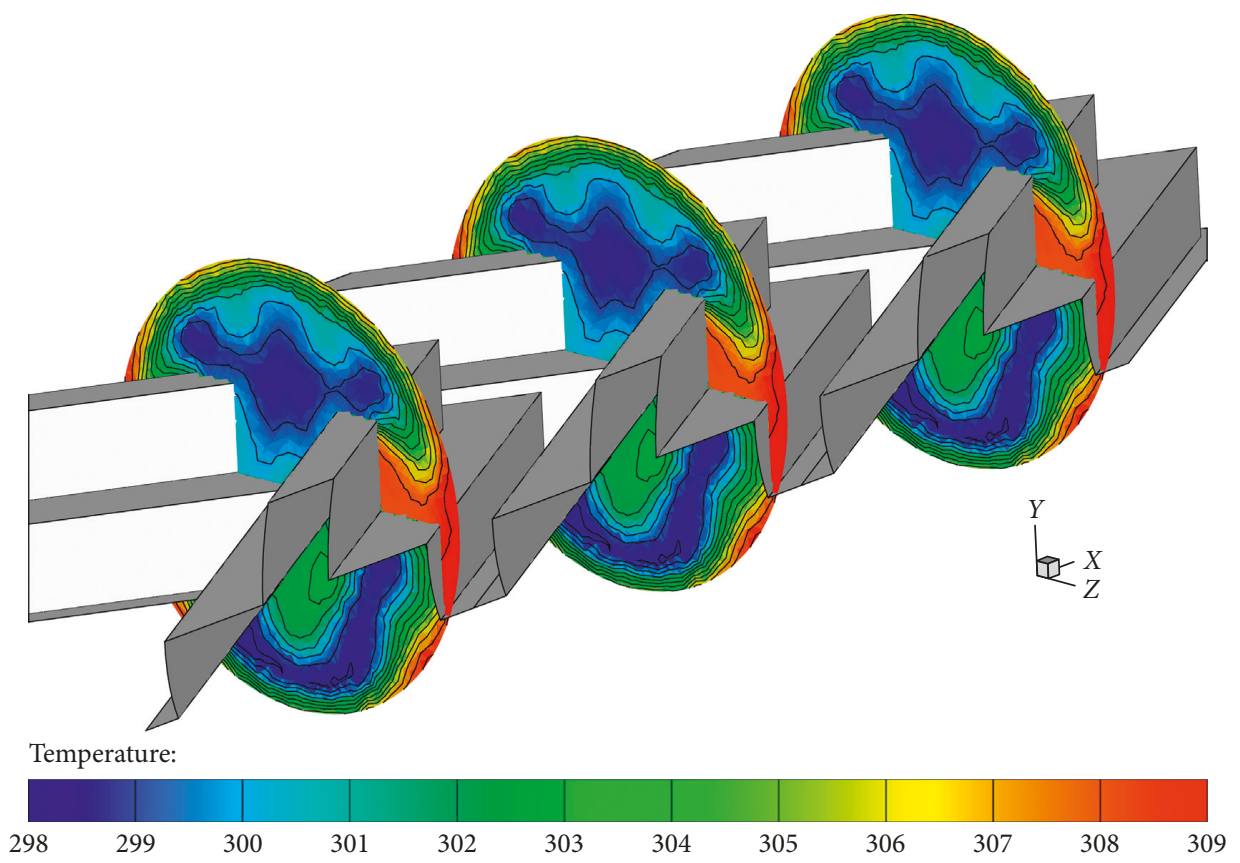

(a)

FIGURE 7: Continued. 


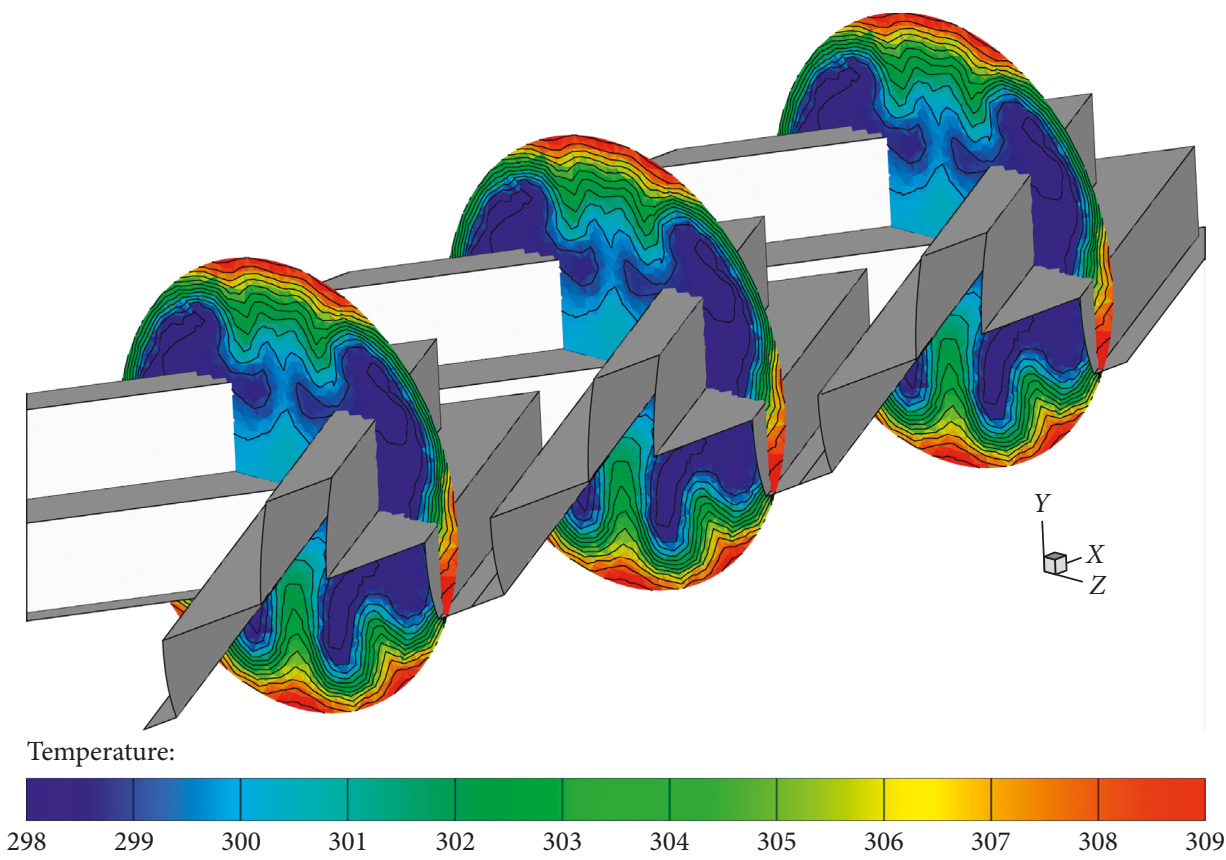

(b)

Figure 7: Temperature contour in transverse planes of the heat exchanger tube inserted with V-wavy surface at $\alpha=30^{\circ}$ and Re $=600$ for (a) V-Downstream and (b) V-Upstream.

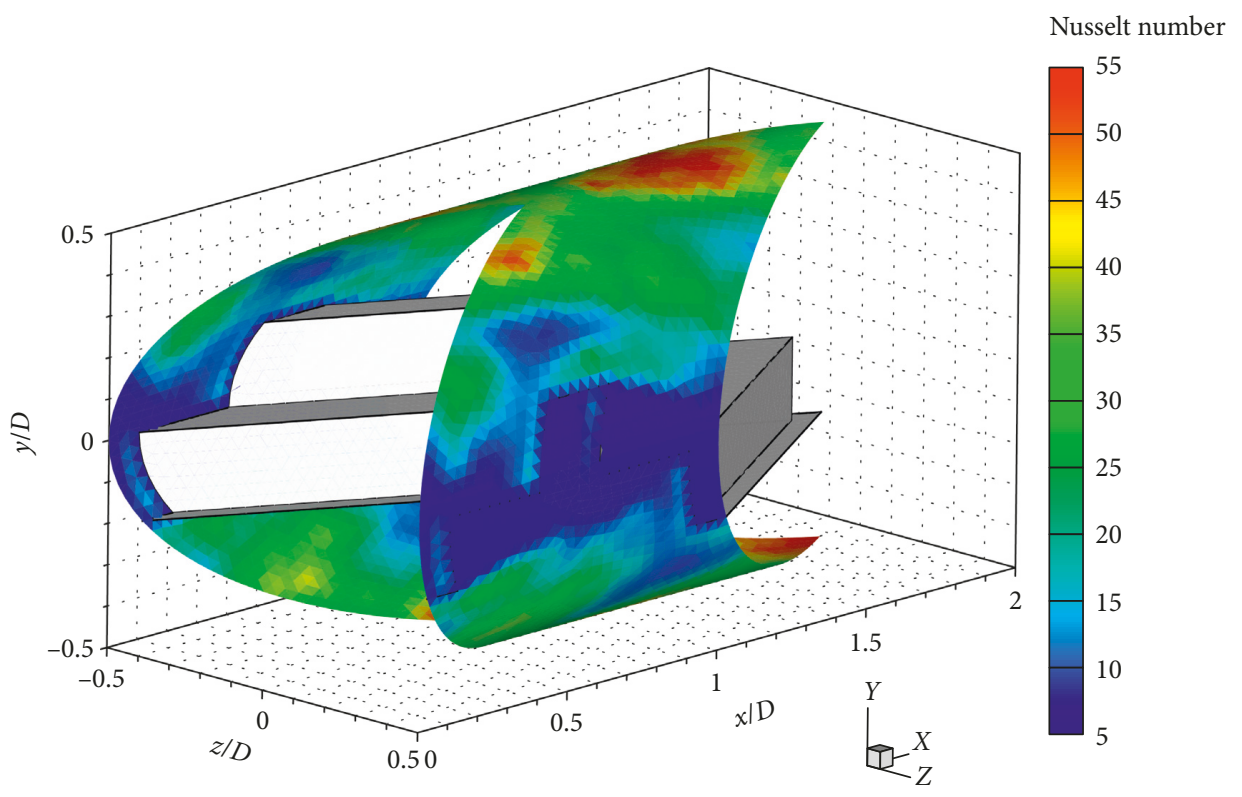

(a)

Figure 8: Continued. 


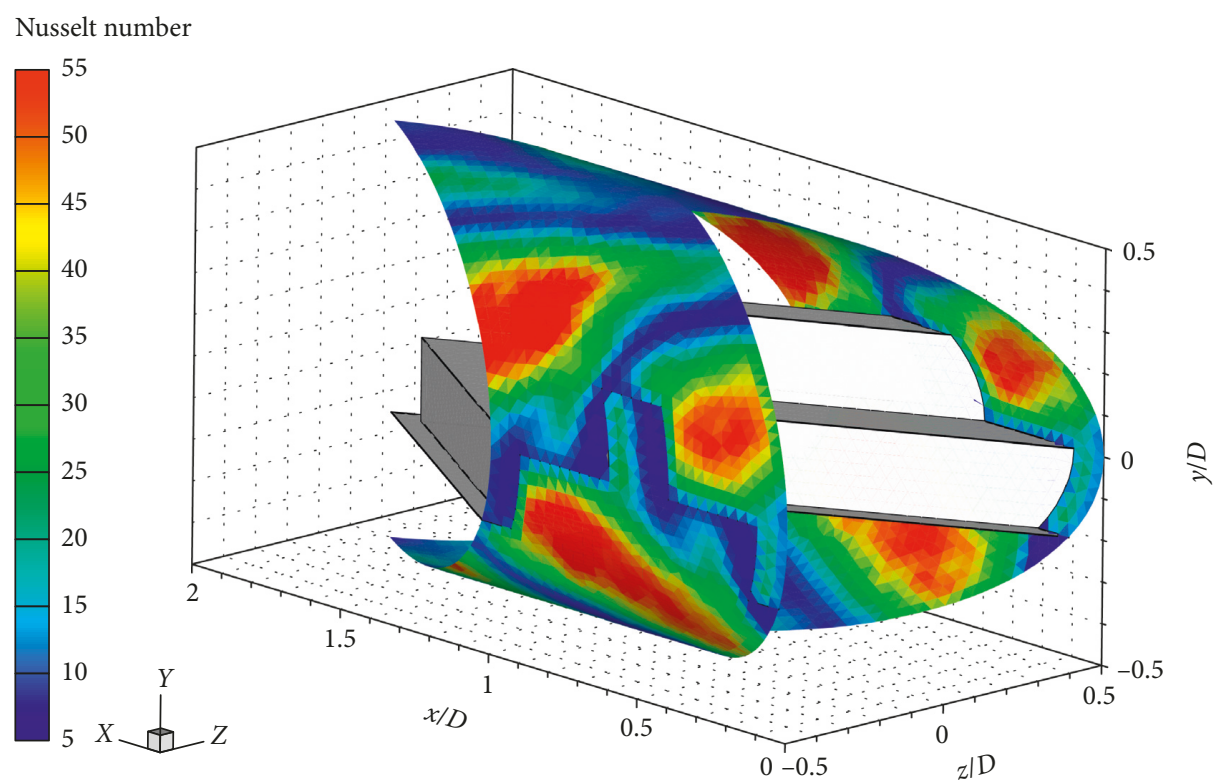

(b)

FIGURE 8: Local Nusselt number contour on the tube wall of the heat exchanger tube inserted with the V-wavy surface at $\alpha=30^{\circ}$ and $\operatorname{Re}=600$ for (a) V-Downstream and (b) V-Upstream.

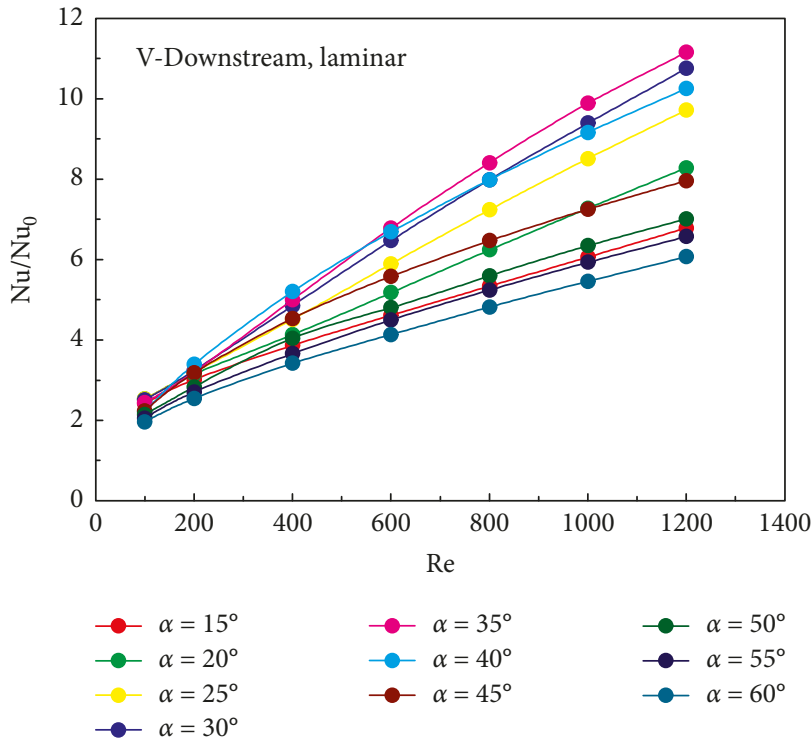

(a)

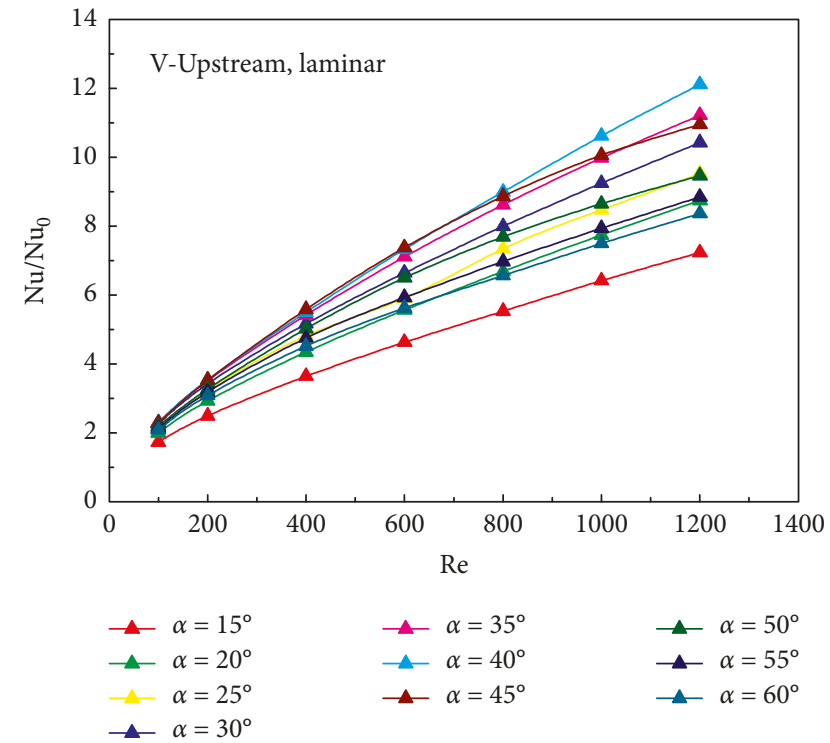

(b)

FIgURE 9: Relations of $\mathrm{Nu} / \mathrm{Nu}_{0}$ with Re for the heat exchanger tube inserted with the $\mathrm{V}$-wavy surface for (a) V-Downstream and (b) VUpstream at the laminar regime.

performs higher friction loss than the smooth circular tube with no wavy surface in all cases $\left(f / f_{0}>1\right)$. The flow attack angles around $15^{\circ}-25^{\circ}$ can help to reduce the pressure of the heating system for both arrangements. $f / f_{0}$ for the V-Downstream wavy surface is found to be around 8.8912.21 and $28.57-71.32$ at Re 100 and 1200 , respectively, and around 9.29-13.03 and 31.16-70.81, respectively, for the V-Upstream wavy surface.
Figures 11(a) and 11(b) display the relations of the TEF with the Reynolds number at various flow attack angles of the V-Downstream and V-Upstream wavy surfaces in the heat exchanger tube, respectively. As shown in the figures, the TEF tends to increase when enhancing the Reynolds number for both arrangements. The $\mathrm{Re}=100$ provides the lowest of TEF, while the maximum TEF is detected at $\mathrm{Re}=$ 1200. Almost in all cases, the insertion of the V-wavy surface 


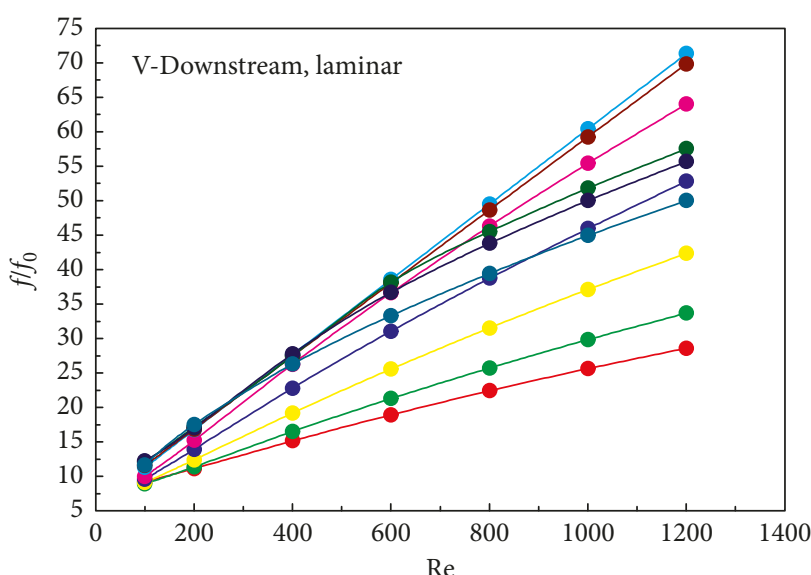

$\multimap \alpha=15^{\circ}$
$\multimap \alpha=20^{\circ}$
$-\alpha=25^{\circ}$
$\multimap \alpha=30^{\circ}$ $\longrightarrow \alpha=50^{\circ}$

$-\alpha=55^{\circ}$

$\longrightarrow \alpha=60^{\circ}$

(a)

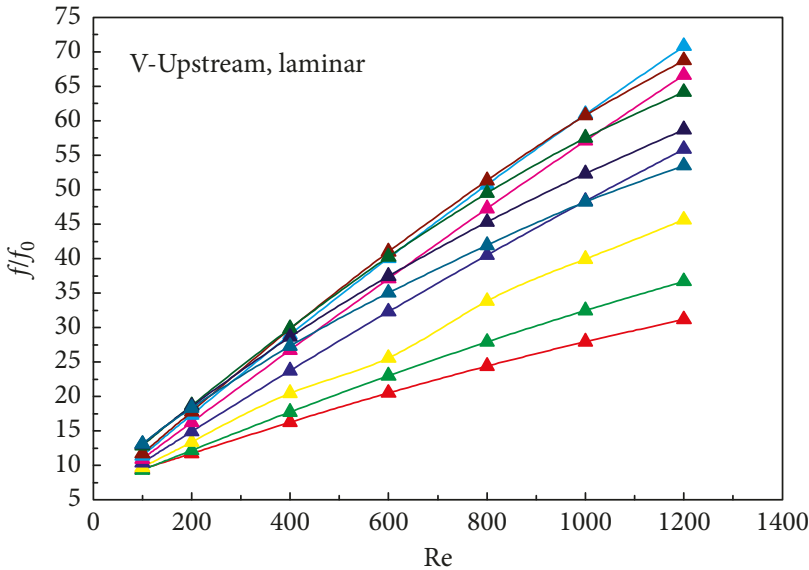

$\neg \alpha=15^{\circ}$

$\therefore \alpha=20^{\circ}$

$\alpha=25^{\circ}$

$\neg \alpha=30^{\circ}$

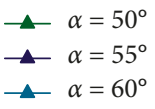

(b)

FIGURE 10: Relations of $f / f_{0}$ with Re for the heat exchanger tube inserted with the V-wavy surface for (a) V-Downstream and (b) V-Upstream at the laminar regime.
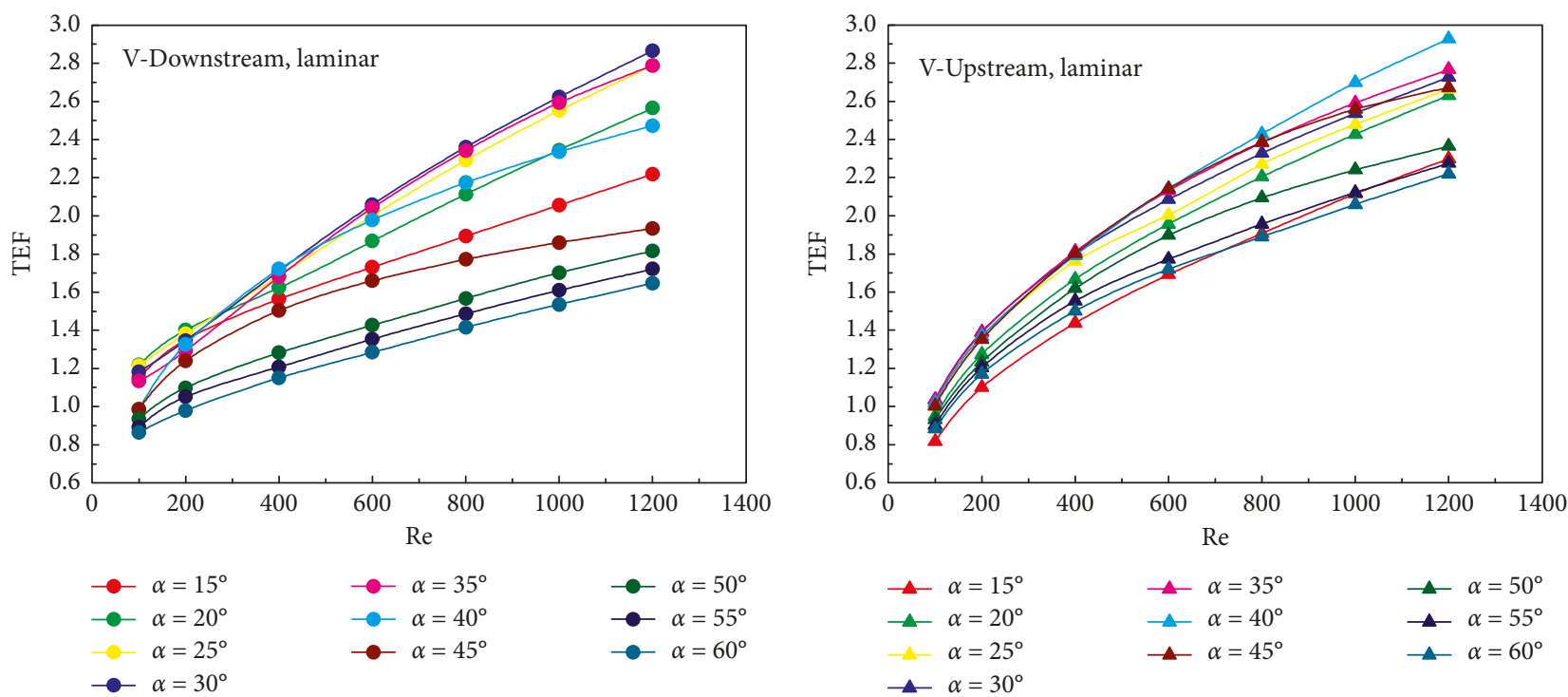

(a)

$$
\begin{aligned}
& -\alpha=15^{\circ} \\
& -\alpha=20^{\circ} \\
& -\alpha=25^{\circ} \\
& \_\alpha=30^{\circ}
\end{aligned}
$$

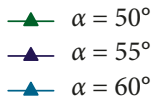

(b)

FIGURE 11: Relations of the TEF with Re for the heat exchanger tube inserted with the V-wavy surface for (a) V-Downstream and (b) VUpstream at the laminar regime.

in the heating tube performs higher thermal performance than the smooth tube without the $\mathrm{V}$-wavy surface (TEF $>1$ ). For $\mathrm{V}$-Downstream, the TEF is around $0.86-1.22$ and 1.64-2.87, respectively, for $\mathrm{Re}=100$ and 1200 . For $\mathrm{V}-\mathrm{Up}$ stream, the TEF is around $0.88-1.04$ and $2.22-2.93$ for $\mathrm{Re}=$ 100 and 1200 , respectively.

Figures 12 (a) and 12(b) plot the variations of $\mathrm{Nu} / \mathrm{Nu}_{0}$ with the flow attack angle for the tube heat exchanger inserted with the $\mathrm{V}$-wavy surface for $\mathrm{V}$-Downstream and
V-Upstream arrangements, respectively. Considering at $\operatorname{Re}=1200$, the optimum $\mathrm{Nu} / \mathrm{Nu}_{0}$ is detected at the flow attack angle of $35^{\circ}$ for the $\mathrm{V}$-Downstream, while around $40^{\circ}$ for $\mathrm{V}$-Upstream.

The relations of $f / f_{0}$ with the flow attack angle for the heat exchanger tube inserted with the $\mathrm{V}$-wavy surface are displayed in Figures 13(a) and 13(b), respectively, for V-Downstream and V-Upstream arrangements. Considering at $\operatorname{Re}=1200$, the maximum friction loss in the heating 


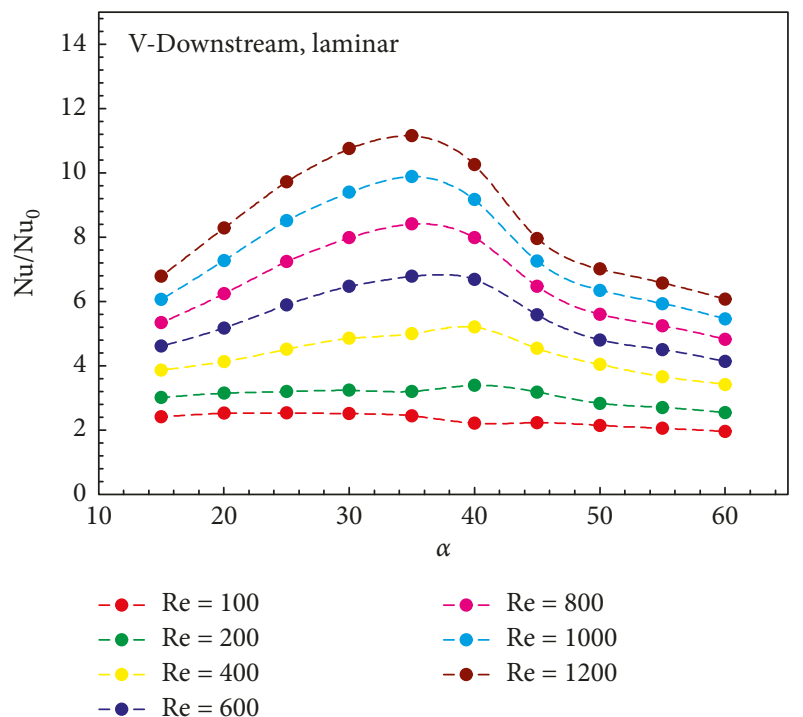

(a)

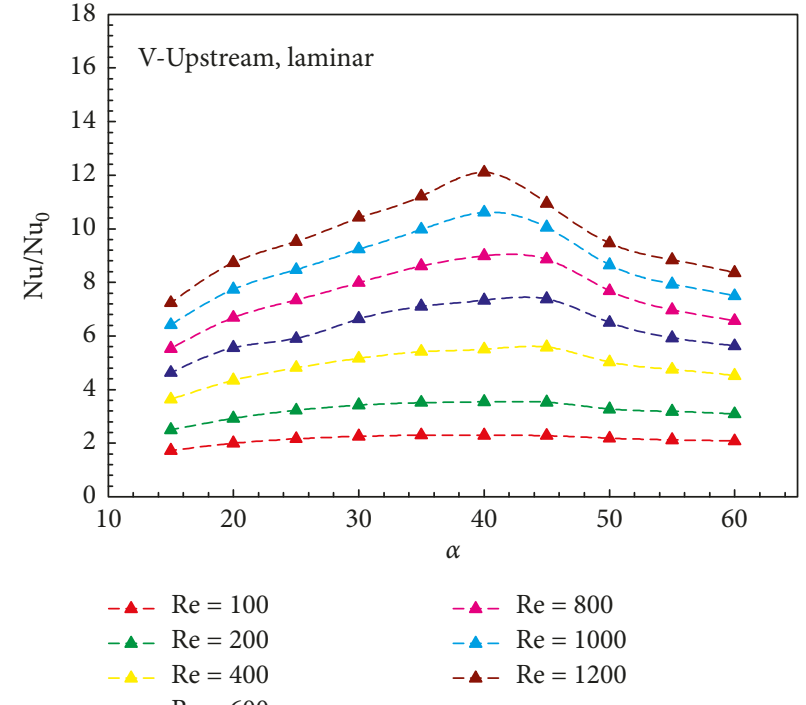

(b)

Figure 12: Relations of $\mathrm{Nu} / \mathrm{Nu}_{0}$ with $\alpha$ for the heat exchanger tube inserted with the V-wavy surface for (a) V-Downstream and (b) VUpstream at the laminar regime.

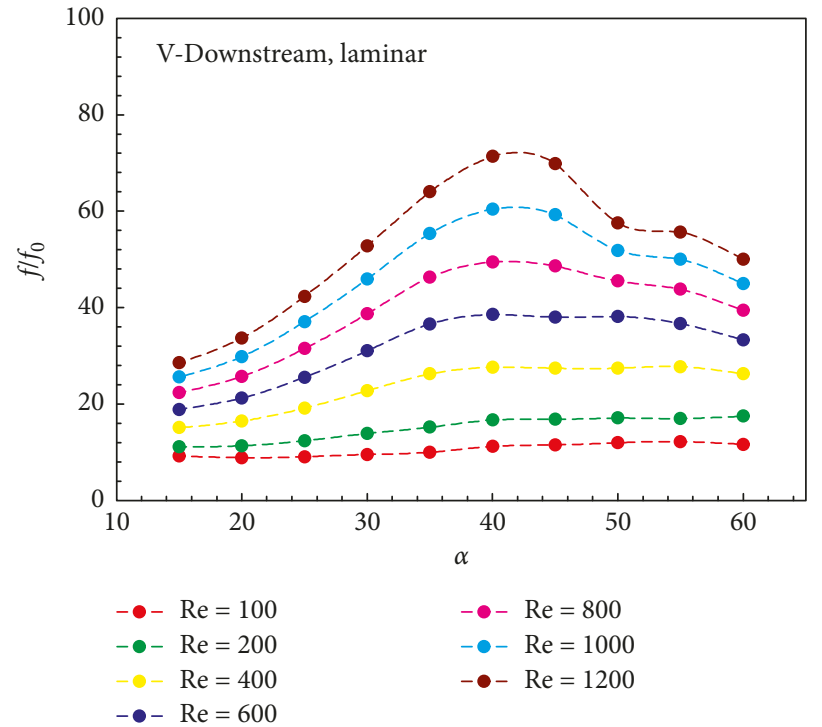

(a)

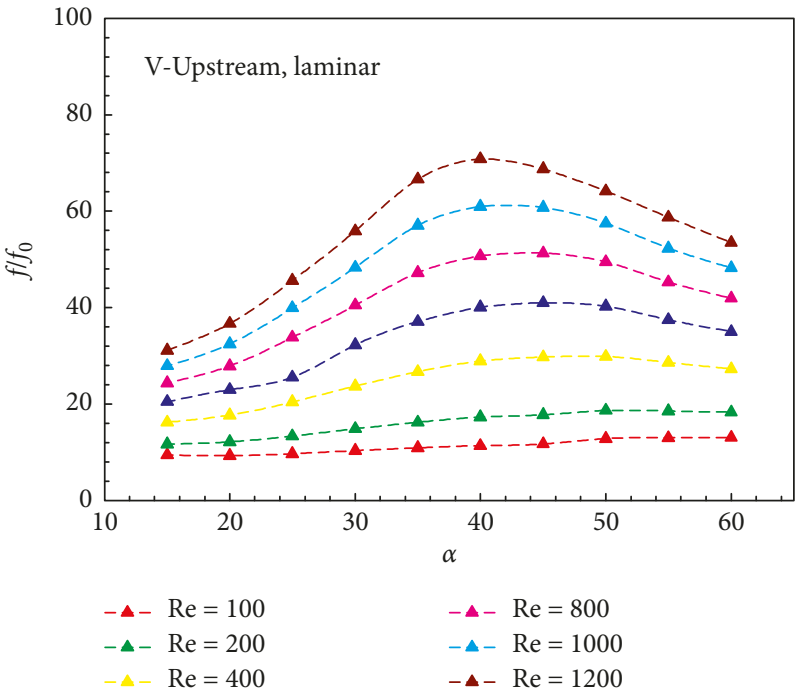

(b)

FIGURE 13: Relations of $f / f_{0}$ with $\alpha$ for the heat exchanger tube inserted with the V-wavy surface for (a) V-Downstream and (b) V-Upstream at the laminar regime.

system is detected at the flow attack angle of $40^{\circ}$ for both arrangements.

The relations of the TEF with the flow attack angle for the heating tube inserted with the $\mathrm{V}$-wavy surface are depicted as Figures 14(a) and 14(b), respectively. As shown in the figures, it is found that the optimum attack angles for the $\mathrm{V}$-Downstream and $\mathrm{V}$-Upstream wavy surfaces are $30^{\circ}$ and $40^{\circ}$, respectively. In addition, the terrible attack angle, which gives the lowest thermal performance for both arrangements, is $60^{\circ} \mathrm{V}$-wavy surface.

\subsection{Turbulent Flow}

6.2.1. Flow and Heat Transfer Configuration. Figures 15(a) and 15(b) plot the $\lambda_{2}$ isosurface of the heat exchanger tube 


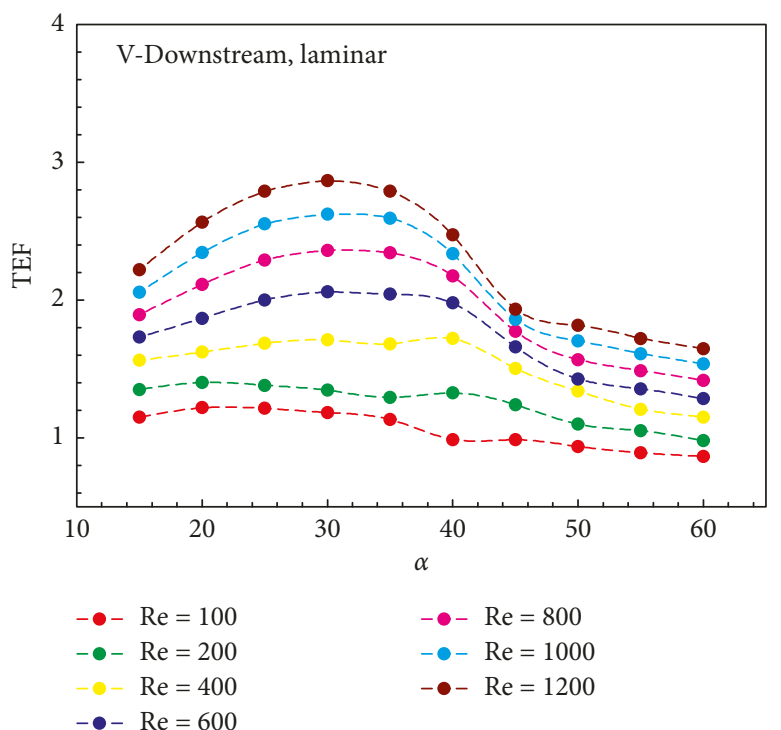

(a)

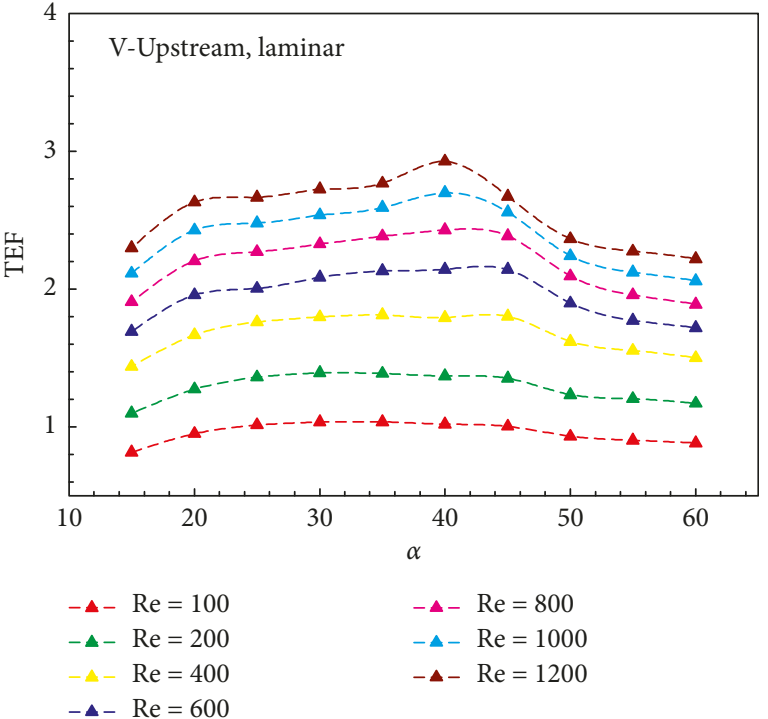

(b)

FIGURE 14: Relations of the TEF with $\alpha$ for the heat exchanger tube inserted with the V-wavy surface for (a) V-Downstream and (b) VUpstream at the laminar regime.

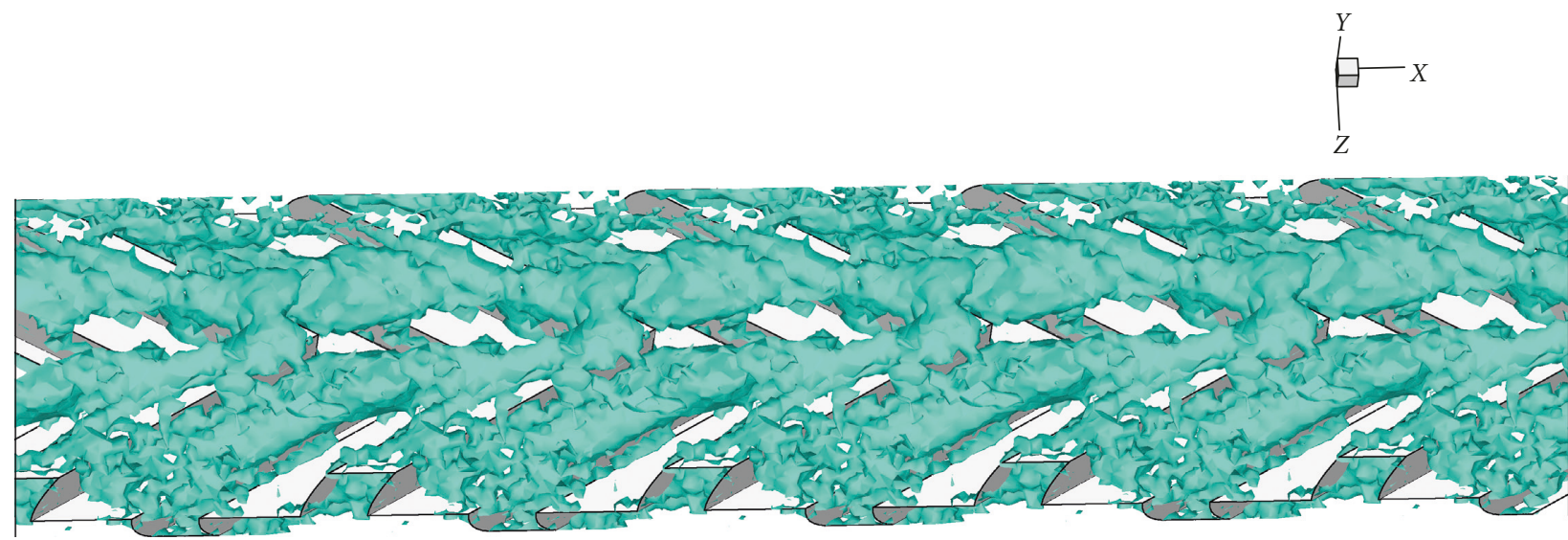

(a)

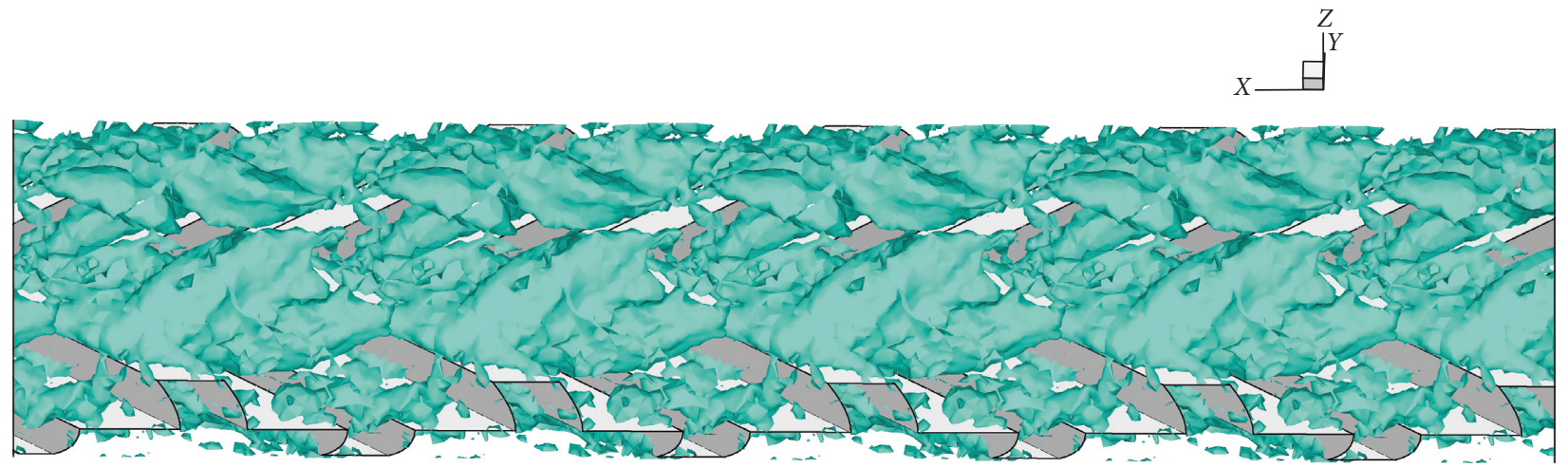

(b)

Figure 15: $\lambda_{2}$ isosurface of the heat exchanger tube inserted with the V-wavy surface at $\alpha=30^{\circ}$ and $\operatorname{Re}=6000$ for (a) V-Downstream and (b) V-Upstream. 


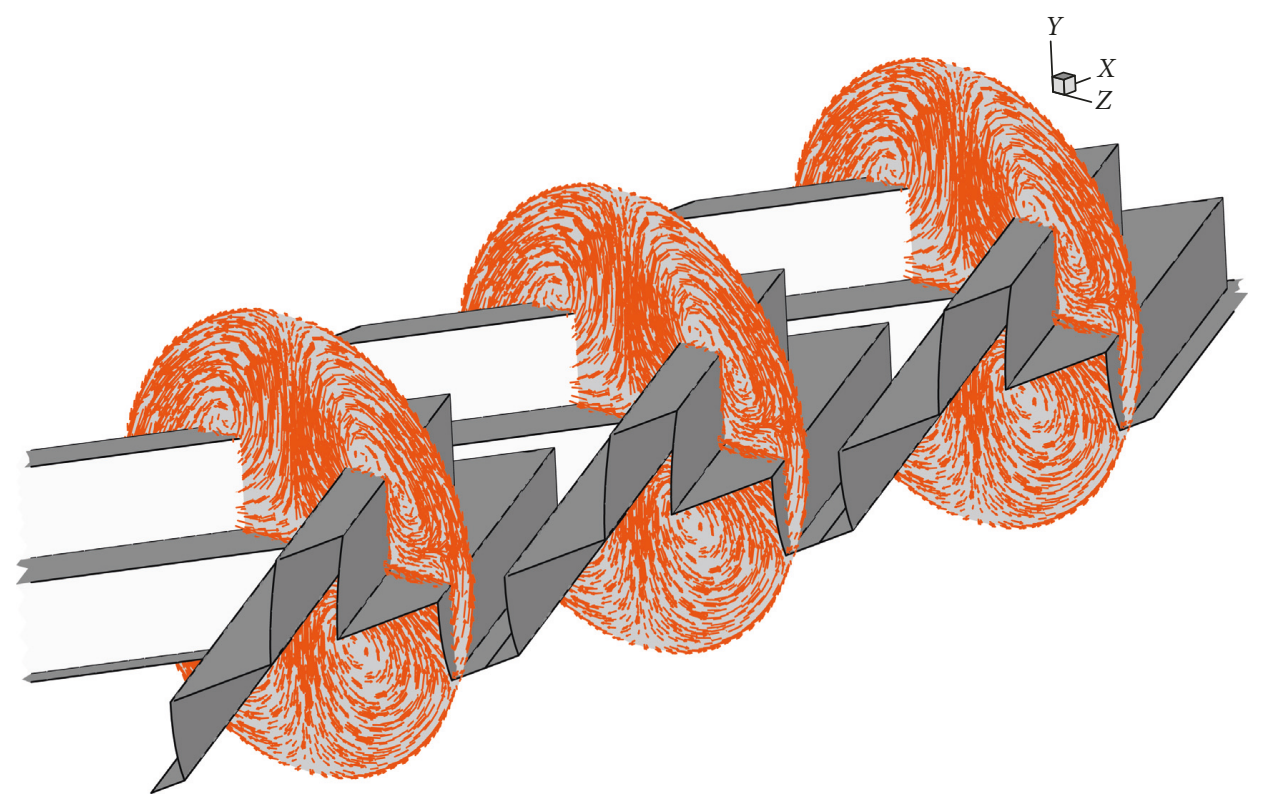

(a)

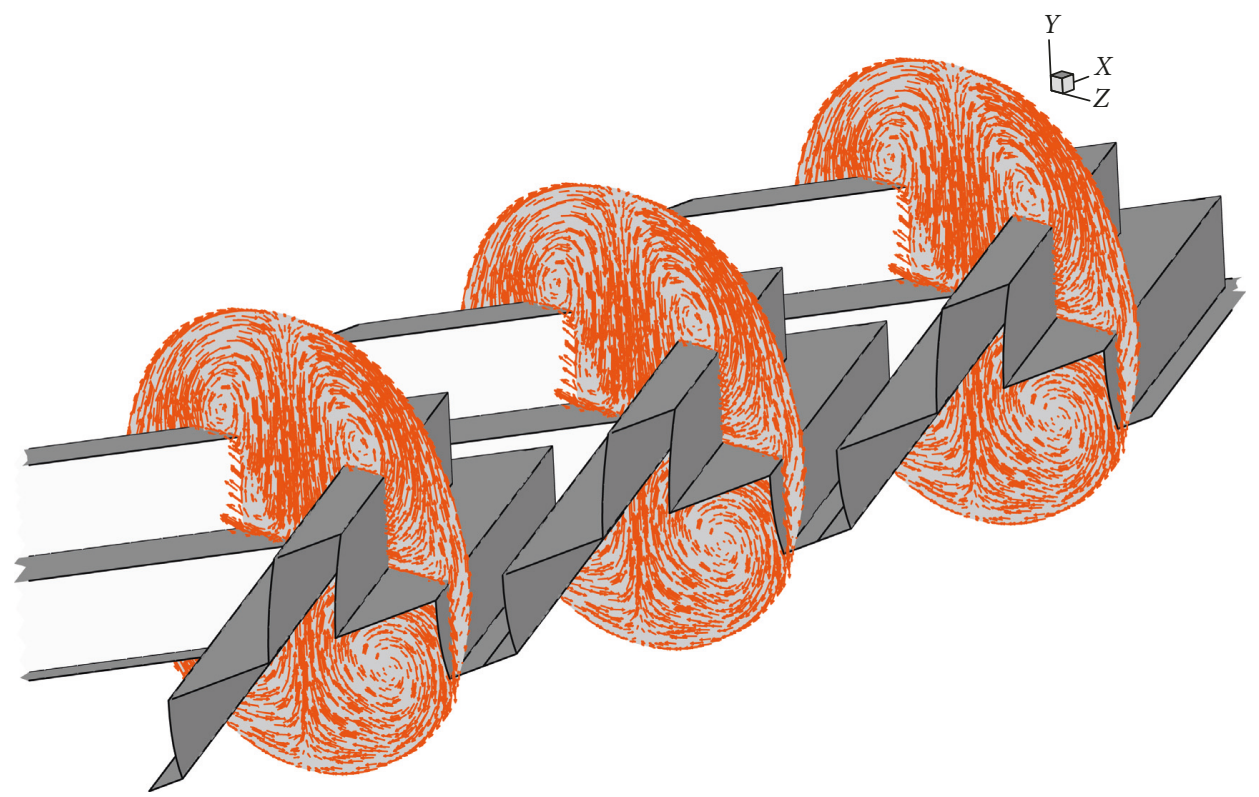

(b)

FIGURE 16: Tangential velocity vector in transverse planes of the heat exchanger tube inserted with the $\mathrm{V}$-wavy surface at $\alpha=30^{\circ}$ and $\mathrm{Re}=$ 6000 for (a) V-Downstream and (b) V-Upstream.

inserted with the V-wavy surface for $\mathrm{V}$-Downstream and $\mathrm{V}$-Upstream, respectively, at $\operatorname{Re}=6000$ and $\alpha=30^{\circ}$. The vortex core is found for both arrangements of the $\mathrm{V}$-wavy surface in the test section. The configuration of the flow is nearly detected as the laminar flow regime, but the vortex strength is not equal.

Figures 16(a) and 16(b) plot the tangential velocity vector in transverse planes for the heat exchanger tube inserted with V-Downstream and V-Upstream wavy surfaces, respectively, at $\operatorname{Re}=6000$ and $\alpha=30^{\circ}$. As seen in the figures, the $\mathrm{V}$-wavy surface can produce the vortex flow through the test section. The vortex flow helps a better fluid mixing between hot fluid near the tube wall and cold fluid at the center of the test tube. The four main vortex flows are found for both arrangements. Considering at the upper pair of the vortex flow, the $\mathrm{V}$-Downstream wavy surface creates the counterrotating flow with common-flow-up, while the V-Upstream wavy surface produces the counterrotating flow with common-flow-down. The different flow structure in the test section effects for the different heat transfer behavior.

Figures 17 (a) and 17(b) report the longitudinal vortex flow in the test section inserted with the V-wavy surface with 


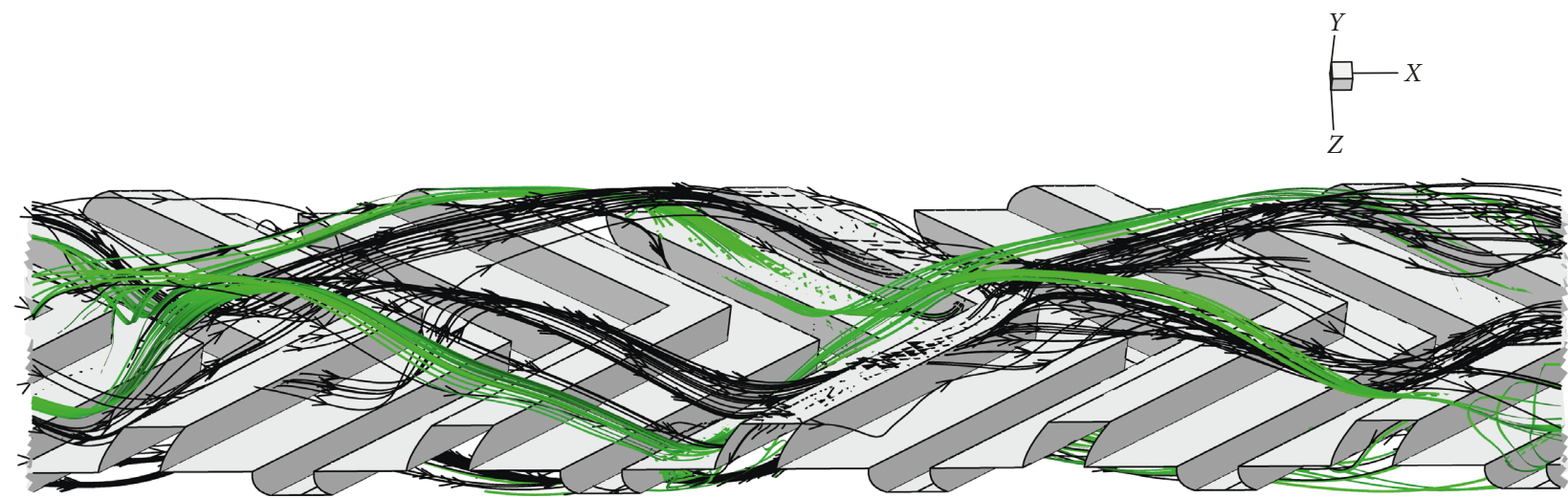

(a)

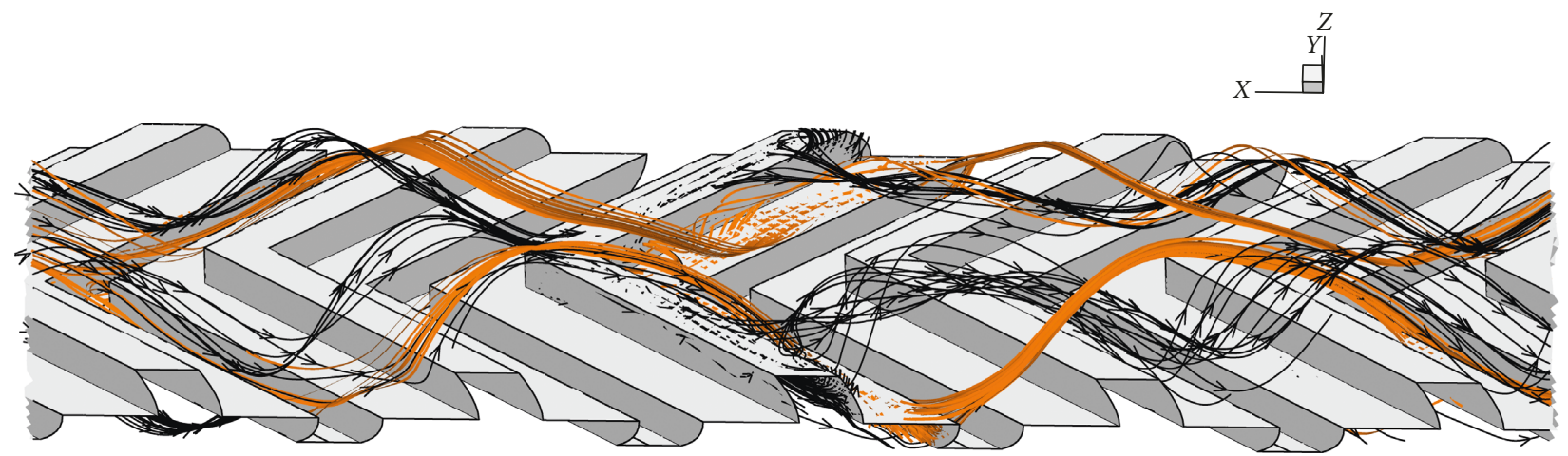

(b)

FIgURE 17: Longitudinal vortex flow of the heat exchanger tube inserted with the V-wavy surface at $\alpha=30^{\circ}$ and $\mathrm{Re}=6000$ for (a) VDownstream and (b) V-Upstream.

$\mathrm{V}$-Downstream and V-Upstream, respectively, at $\mathrm{Re}=6000$ and $\alpha=30^{\circ}$. The $\mathrm{V}$-wavy surface in the heat exchanger tube produces the longitudinal vortex flow through the test section on both arrangements. The swirling flow slides on the wavy groove from the sidewall to the V-tip for $\mathrm{V}$-Downstream. The $\mathrm{V}$-Upstream produces the swirling flow, which slides on the wavy groove from the V-tip to the sidewall. The vortex flow is an important factor to augment heat transfer rate and thermal performance due to the vortex flow that disturbs the thermal boundary layer on the heat transfer surface.

The turbulent kinetic energy (TKE) distributions in transverse planes for the heat exchanger tube equipped with V-Downstream and V-Upstream wavy surfaces are plotted as Figures 18(a) and 18(b), respectively, at $\mathrm{Re}=$ 6000 and $\alpha=30^{\circ}$. The high TKE is detected when inserting the wavy $\mathrm{V}$-surface in the heat exchanger tube for both arrangements.

Figures 19(a) and 19(b) report the temperature distributions in transverse planes for the heat exchanger tube equipped with the $\mathrm{V}$-wavy surface for $\mathrm{V}$-Downstream and $\mathrm{V}$-Upstream arrangements, respectively, at $\mathrm{Re}=6000$ and $\alpha$ $=30^{\circ}$. As shown in the figures, the insertion of the wavy $\mathrm{V}$-surface in the tube helps a better fluid mixing for both cases. The lower temperature of the air (a blue contour) moves from the center of the test section to the tube surface. The high temperature of the air (a red layer) seems to be thinner.

The local Nusselt number distributions on the heat transfer surface for the heat exchanger tube inserted with the V-wavy surface are created as Figures 20(a) and 20(b), respectively, at $\operatorname{Re}=6000$ and $\alpha=30^{\circ}$. The presence of the $\mathrm{V}$-wavy surface in the tube heat exchanger provides higher heat transfer rate than the smooth circular tube with no wavy surface for both cases. The thermal boundary layer is disturbed by the vortex flow which was created from the $\mathrm{V}$-wavy surface. The thermal boundary layer disturbance, vortex flow, and impinging flow are important factors for heat transfer and thermal performance improvement.

6.2.2. Performance Assessment. Figures 21(a) and 21(b) present the variations of $\mathrm{Nu} / \mathrm{Nu}_{0}$ with the Reynolds number at various flow attack angles for $\mathrm{V}$-Downstream and $\mathrm{V}$-Upstream wavy surfaces in the heat exchanger tube, respectively. As shown in the figures, the heating tube with the $\mathrm{V}$-wavy surface gives higher heat transfer rate than the smooth circular tube for both arrangements. $\mathrm{Nu} / \mathrm{Nu}_{0}$ tends to decrease with increasing Reynolds number for all cases. 


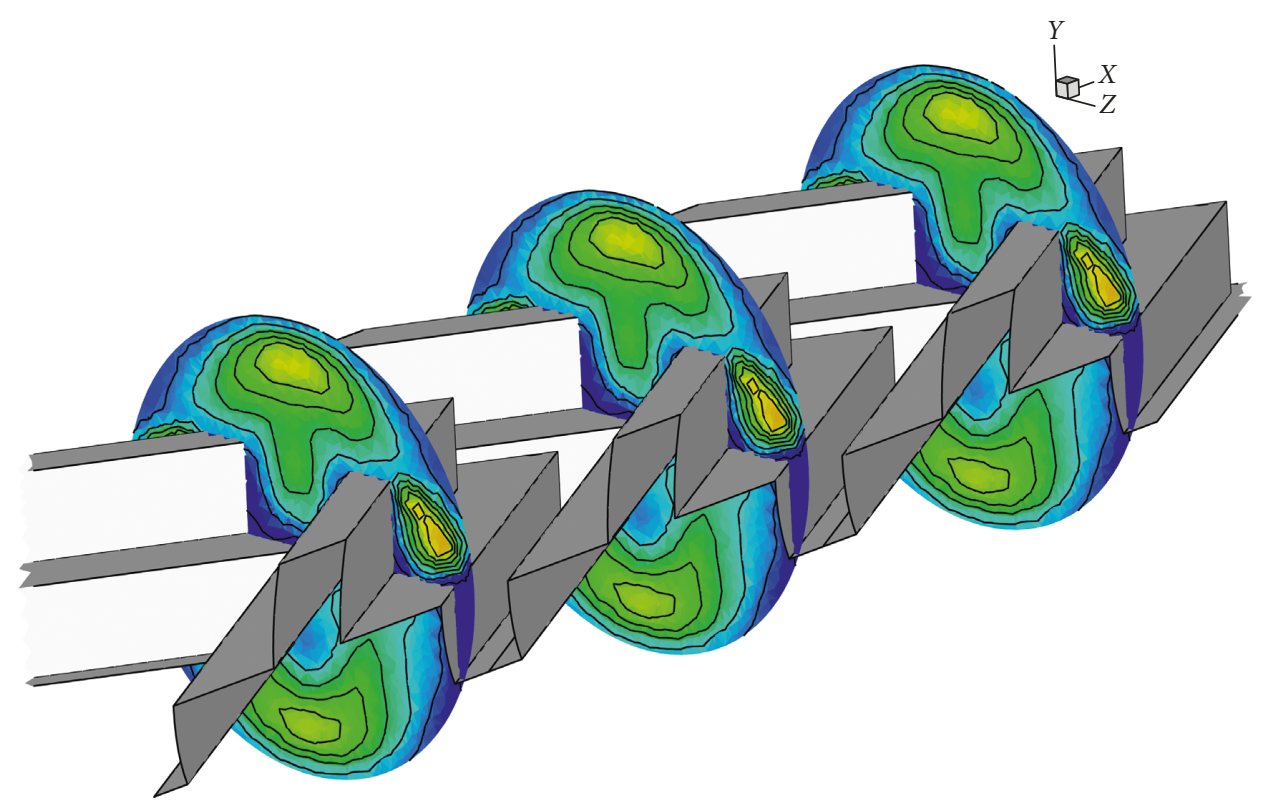

Turbulent kinetic energy:

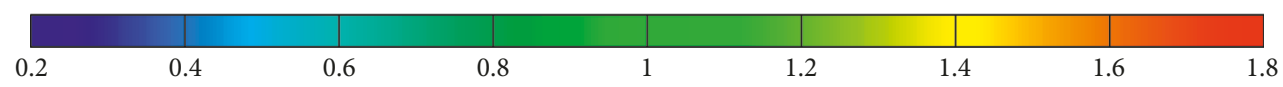

(a)

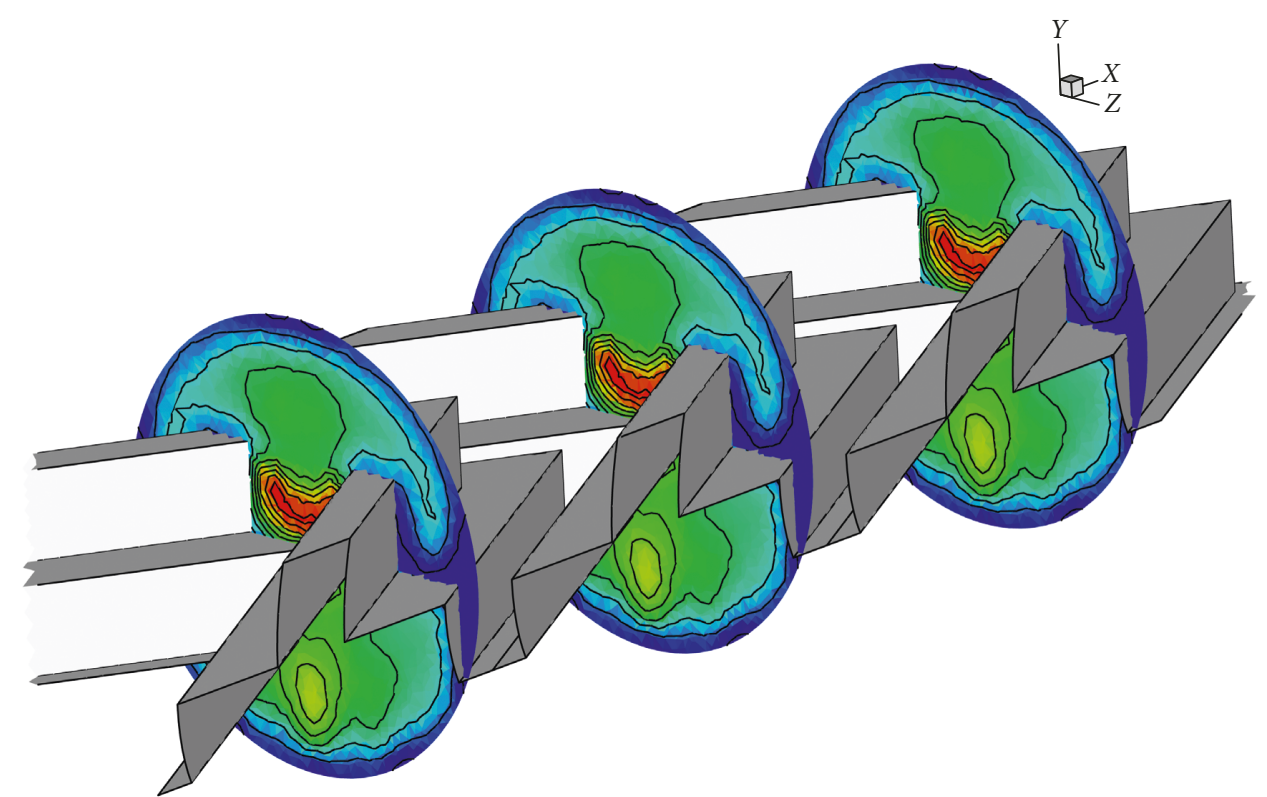

Turbulent kinetic energy:

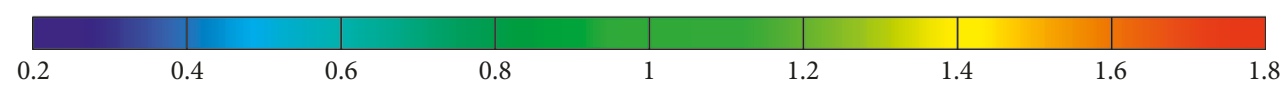

(b)

Figure 18: TKE in transverse planes of the heat exchanger tube inserted with the V-wavy surface at $\alpha=30^{\circ}$ and $\mathrm{Re}=6000$ for (a) VDownstream and (b) V-Upstream.

The $\mathrm{Re}=3000$ performs the highest heat transfer rate, while the $\mathrm{Re}=10000$ provides the reverse result. $\mathrm{Nu} / \mathrm{Nu}_{0}$ is around 5.20-7.00 and 3.40-4.40, respectively, for $\mathrm{Re}=3000$ and 10000 for the V-Downstream wavy surface. The Nusselt number is around 5.35-7.40 and 3.40-4.60 times above the smooth tube, respectively, at $\mathrm{Re}=3000$ and 10000 for the $\mathrm{V}$-Upstream wavy surface.

The relations of $f / f_{0}$ with the Reynolds number at various flow attack angles of the V-wavy surface in the tube heat exchanger are depicted as Figures 22(a) and 22(b), 


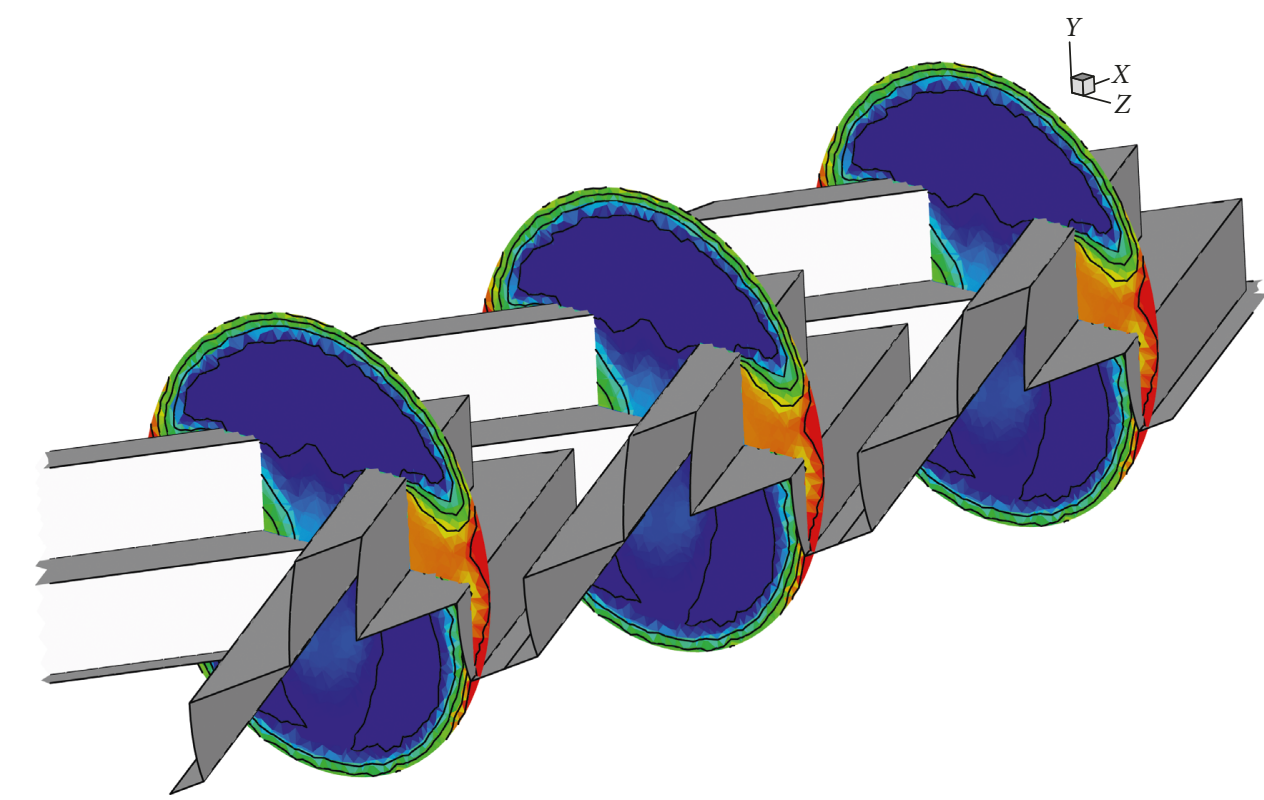

Temperature:

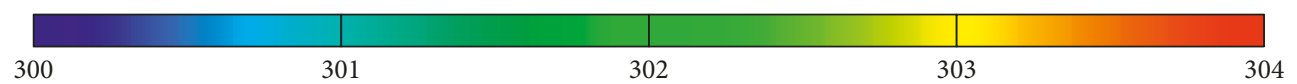

(a)

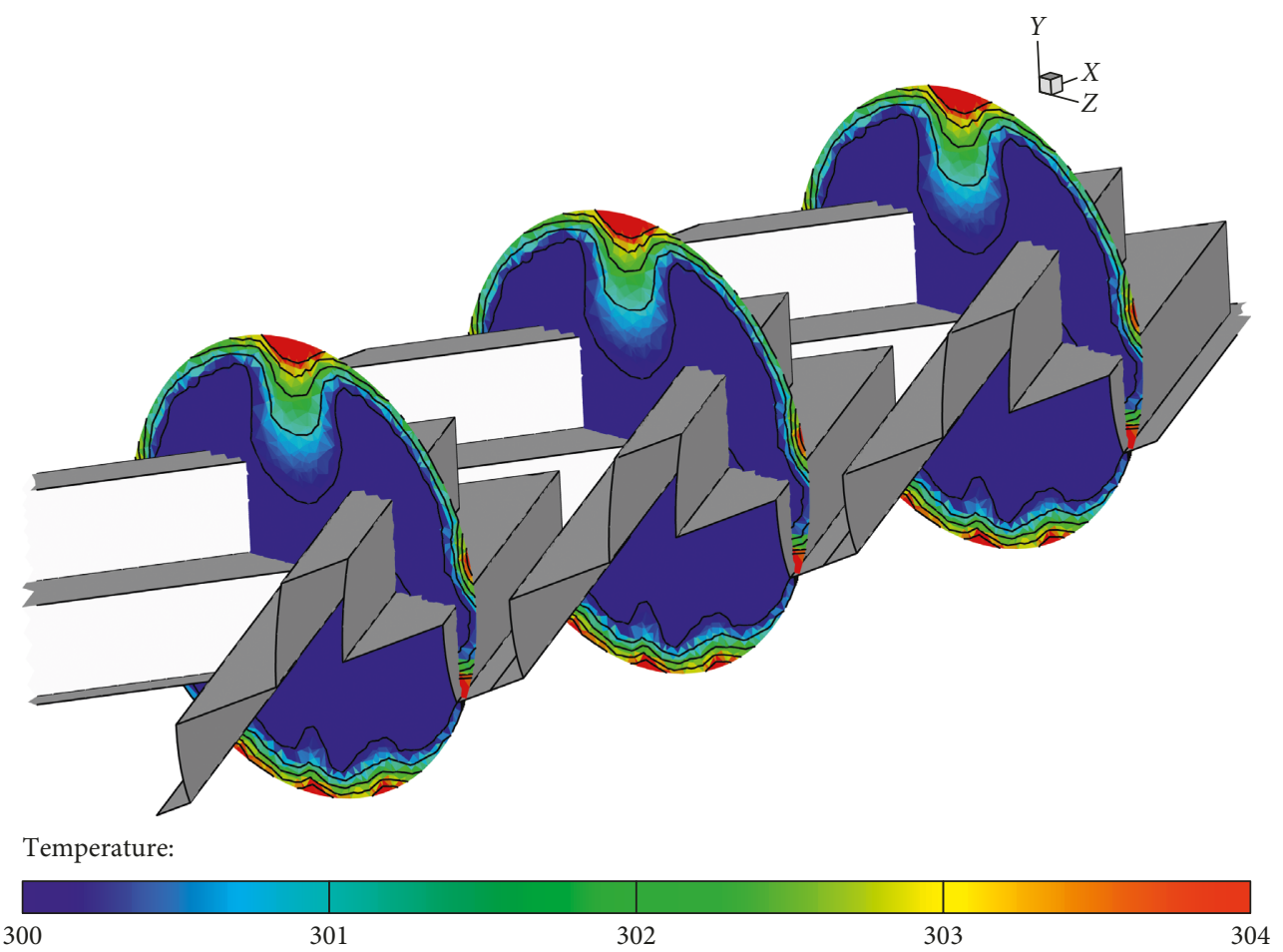

(b)

FIgURE 19: Temperature contour in transverse planes of the heat exchanger tube inserted with the V-wavy surface at $\alpha=30^{\circ}$ and Re $=6000$ for (a) V-Downstream and (b) V-Upstream.

respectively. $f / f_{0}$ is higher than the smooth tube in all cases when inserting the V-wavy surface in the heat exchanger tube. $f / f_{0}$ slightly increases when enhancing the Reynolds number. The peak of the friction loss is detected at $\mathrm{Re}=$ 10000 , while the opposite trend is found at $\operatorname{Re}=3000$. $f / f_{0}$ for the V-Downstream wavy surface in the heat exchanger tube 


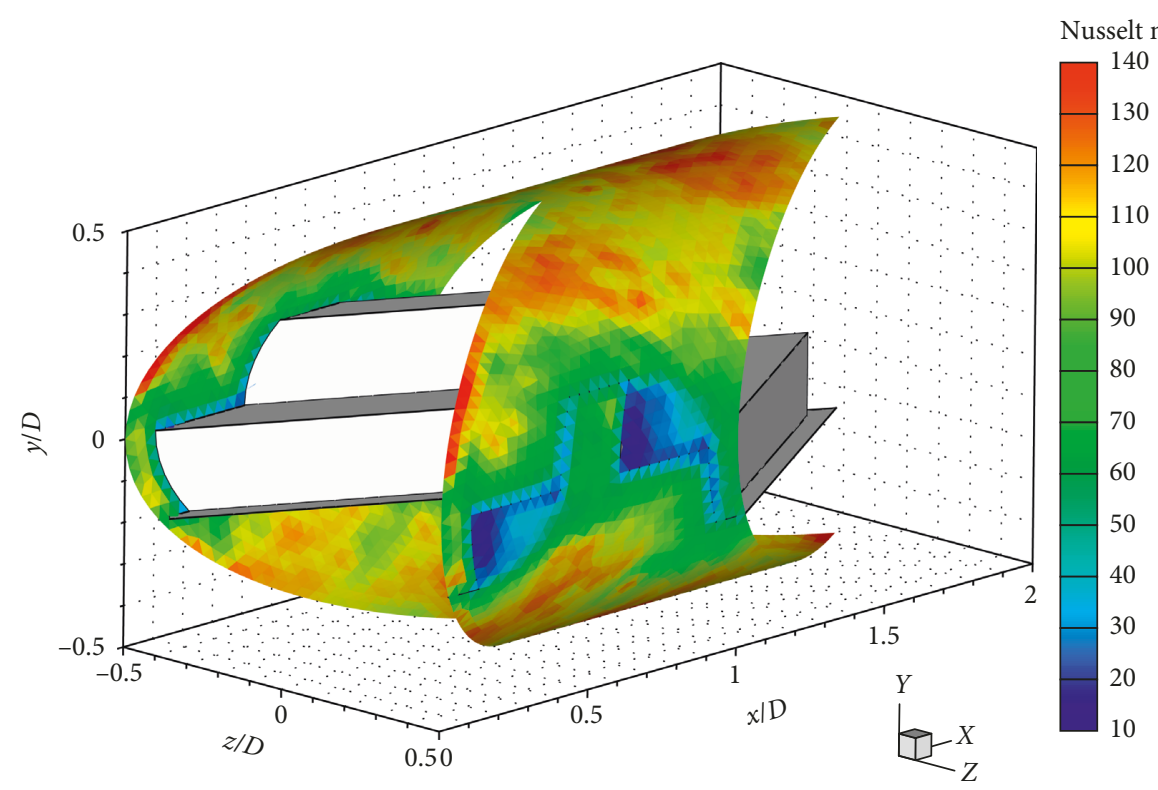

(a)

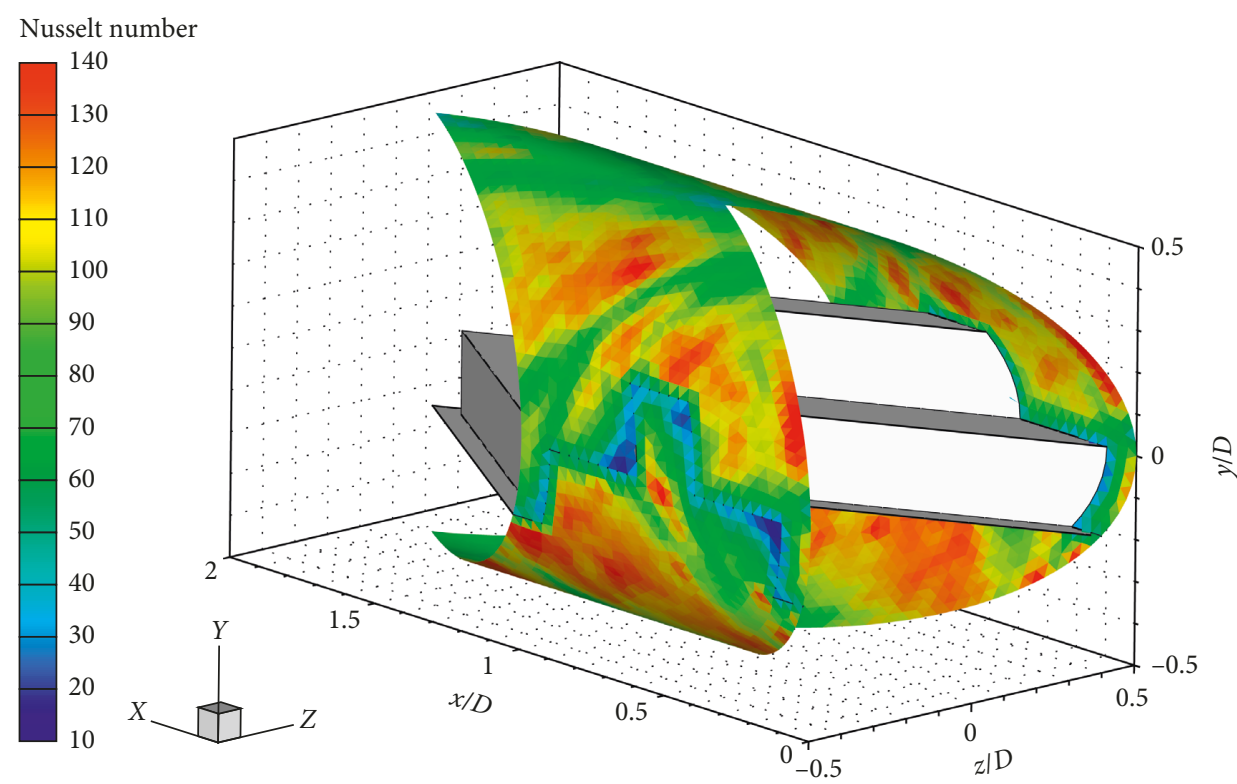

(b)

Figure 20: Local Nusselt number contour on the tube wall of the heat exchanger tube inserted with the V-wavy surface at $\alpha=30^{\circ}$ and $\mathrm{Re}=$ 6000 for (a) V-Downstream and (b) V-Upstream.

is around 20-68 and 22-80, respectively, for $\operatorname{Re}=3000$ and 10000 and around $20-80$ and $22-110$, respectively, for the V-Upstream wavy surface.

Figures 23(a) and 23(b) present the relations between TEF with the Reynolds number with various flow attack angles of the V-Downstream and V-Upstream wavy surfaces in the tube heat exchanger, respectively. Almost in all cases, the insertion of the V-wavy surface in the heat exchanger tube provides greater thermal performance than the smooth tube (TEF $>1)$. The TEF decreases when augmenting the Reynolds number due to the increment of the friction factor and the reduction of the Nusselt number ratio. The maximum TEF is detected at $\mathrm{Re}=3000$, while the reverse trend is found at $\operatorname{Re}=10000$ for both arrangements. As $\mathrm{Re}=3000$, the TEF is around 1.5-2.1 and 1.6-2.0, respectively, for the V-Downstream and V-Upstream arrangements.

The variations of $\mathrm{Nu} / \mathrm{Nu}_{0}$ with the flow attack angles of the $\mathrm{V}$-wavy surface in the tested tube are reported as Figures 24(a) and 24(b), respectively, for V-Downstream and V-Upstream arrangements. The optimum hat transfer rate is found at the flow attack angle around $30^{\circ}-35^{\circ}$ for the V-Downstream and around $40^{\circ}-45^{\circ}$ for the V-Upstream. Considering at $\mathrm{Re}=3000$, the lowest values of the Nusselt number is detected at the flow attack angle around $15^{\circ}$ for both arrangement. The reason is 


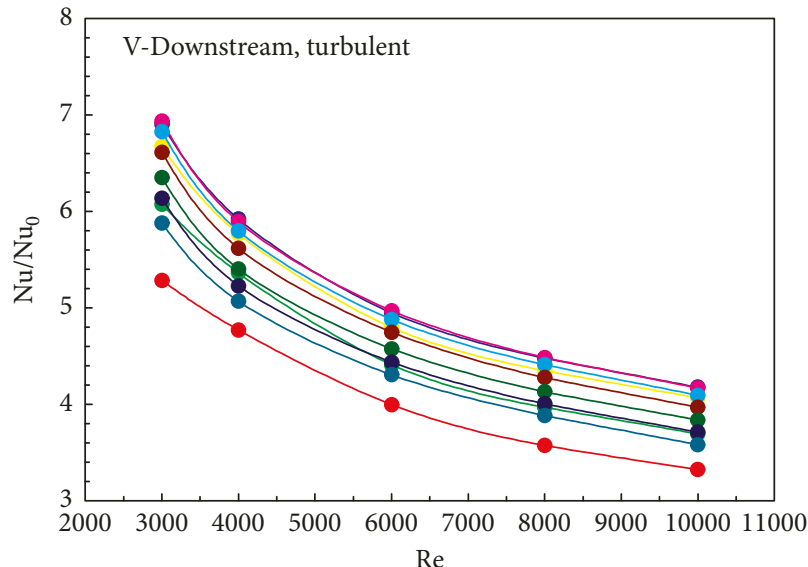

$\mathrm{Re}$

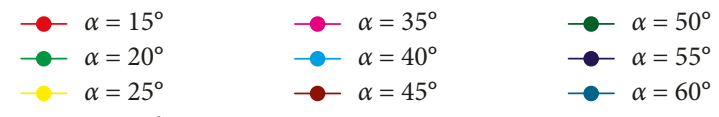

(a)

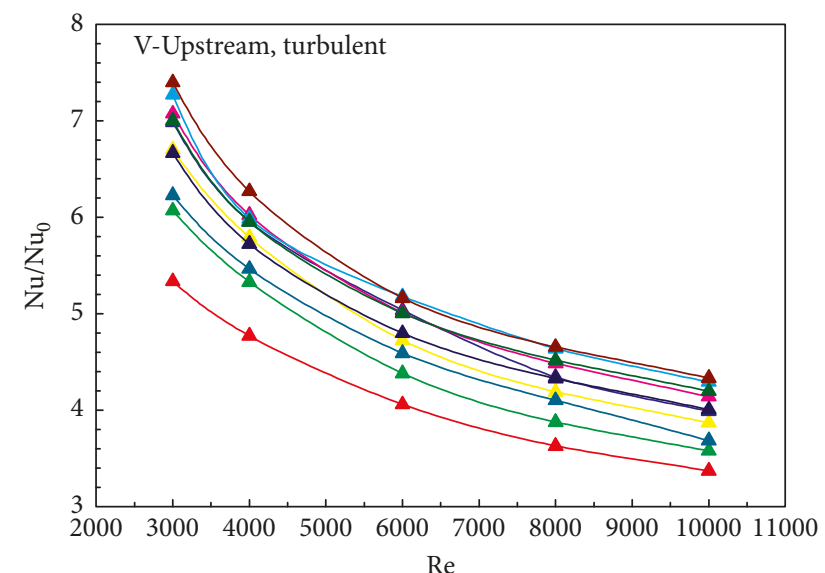

$\therefore-\alpha=15^{\circ}$

$\therefore \alpha=20^{\circ}$

$\alpha=25^{\circ}$

$\multimap \alpha=30^{\circ}$

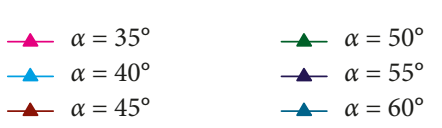

(b)

FIgURE 21: Relations of $\mathrm{Nu} / \mathrm{Nu}_{0}$ with Re for the heat exchanger tube inserted with the V-wavy surface for (a) V-Downstream and (b) VUpstream at the turbulent regime.

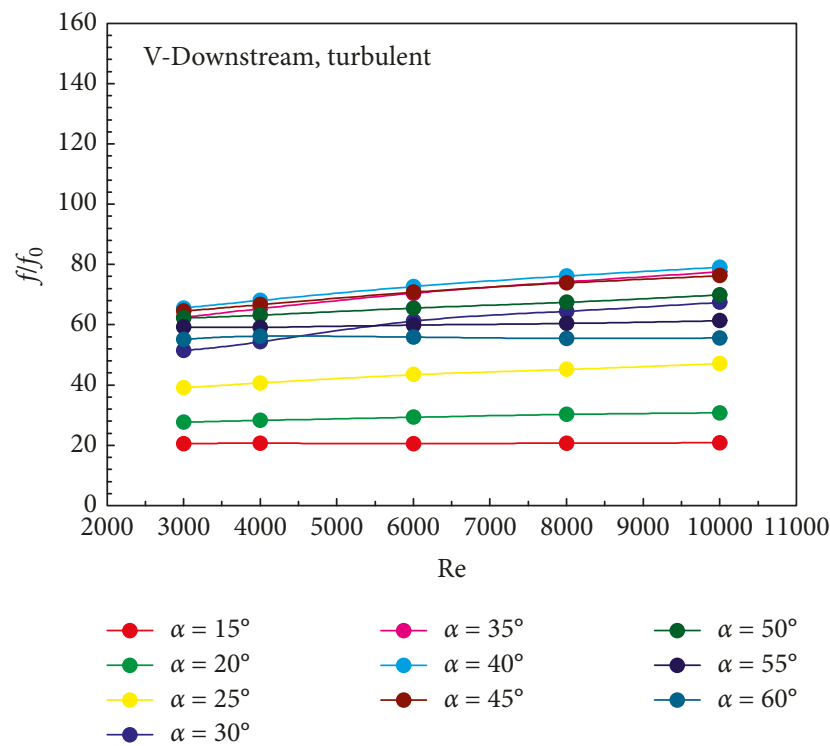

(a)

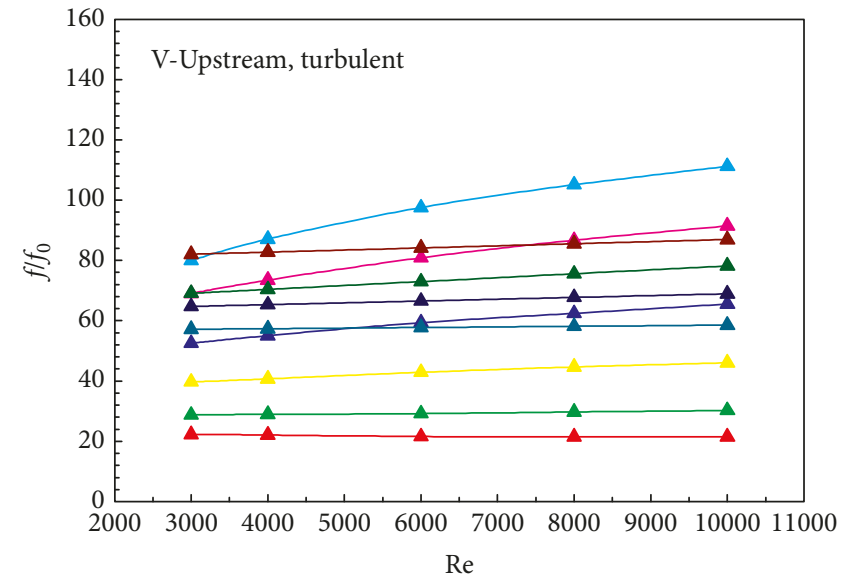

$-\alpha=15^{\circ}$
$-\alpha=20^{\circ}$
$-\alpha=25^{\circ}$
$-\alpha=30^{\circ}$

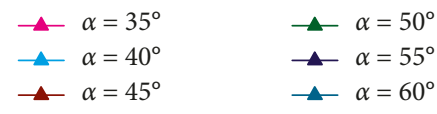

(b)

FIGURE 22: Relations of $f / f_{0}$ with Re for the heat exchanger tube inserted with the V-wavy surface for (a) V-Downstream and (b) V-Upstream at the turbulent regime.

that the $15^{\circ} \mathrm{V}$-wavy surface can produce the lowest strength of the vortex flow.

$f / f_{0}$ versus the flow attack angles for the V-Downstream and $\mathrm{V}$-Upstream wavy surfaces in the test section are depicted as Figures 25(a) and 25(b), respectively. As shown, the maximum friction loss for the present problem is found at the flow attack angle around $40^{\circ}$ for both arrangements. In addition, the low values of the flow attack angle (around $15^{\circ}-20^{\circ}$ ) can help to reduce the pressure loss in the test section.

The relations of the TEF with the flow attack angles for the heat exchanger tube equipped with V-Downstream and V-Upstream wavy surfaces are presented as Figures 26(a) and 26(b), respectively. Although the flow attack angle around 


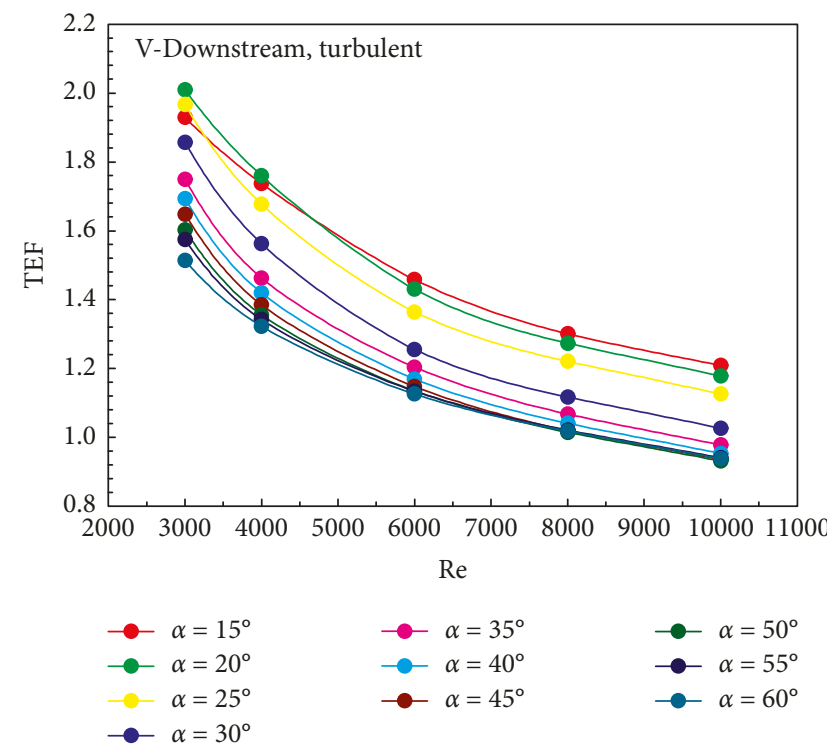

(a)

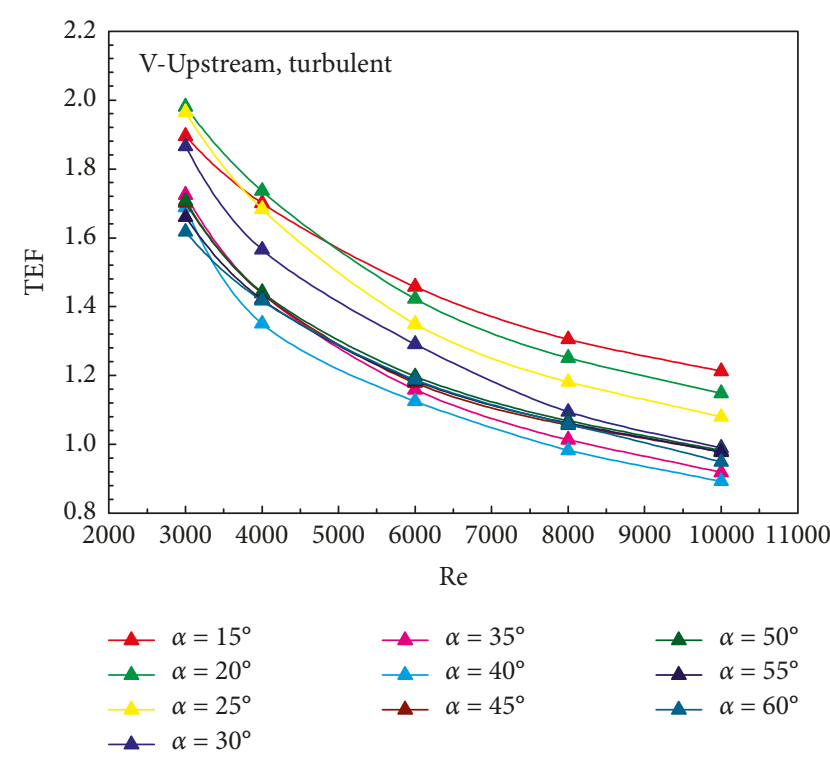

(b)

FIGURE 23: Relations of the TEF with Re for the heat exchanger tube inserted with the V-wavy surface for (a) V-Downstream and (b) VUpstream at the turbulent regime.

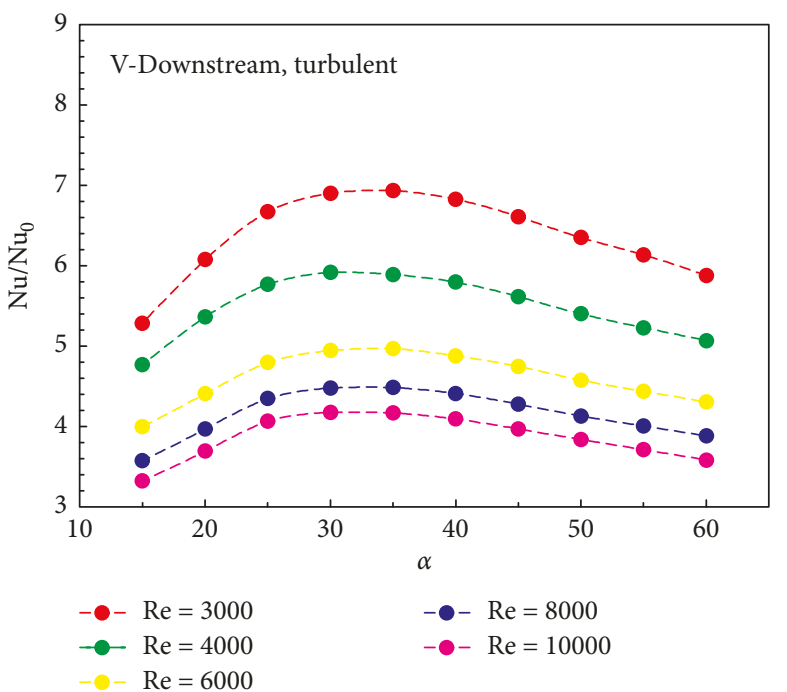

(a)

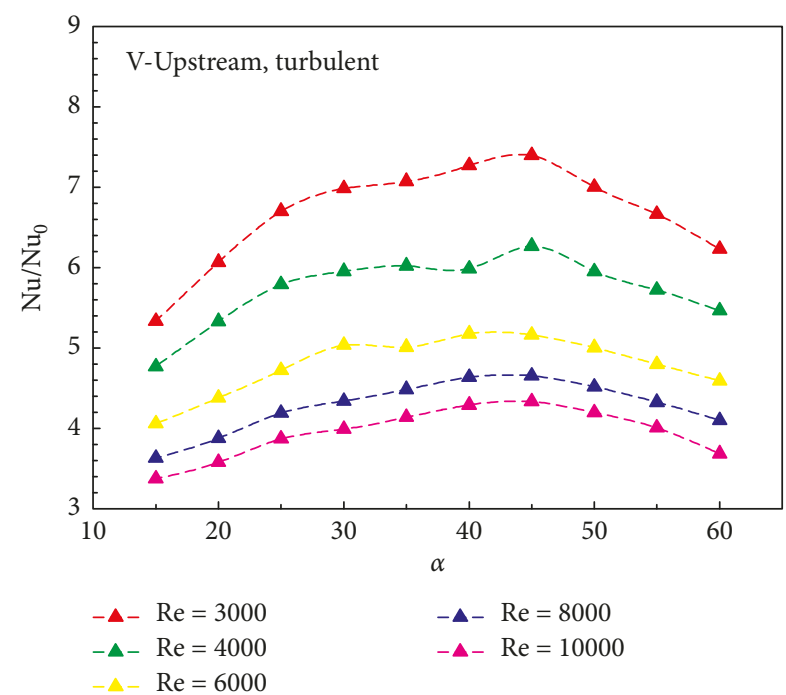

(b)

Figure 24: Relations of $\mathrm{Nu} / \mathrm{Nu}_{0}$ with $\alpha$ for the heat exchanger tube inserted with the $\mathrm{V}$-wavy surface for (a) V-Downstream and (b) VUpstream at the turbulent regime.

$30^{\circ}-45^{\circ}$ gives the highest heat transfer rate, it also provides enlarged pressure loss in the heating system. Therefore, the optimum TEF is found at the flow attack angle around $20^{\circ}$ for both arrangements when considering at $\operatorname{Re}=3000$.

The present results are compared with the previous works $[23,24]$ for the flow attack angle of $45^{\circ}, \mathrm{BR}=0.20$, as Figures 27(a), 27(b), and 27(c) for heat transfer rate, pressure loss, and thermal performance, respectively. Jedsadaratanachai and Jayranaiwachira [23] studied the heat transfer rate and thermal performance in a tube heat exchanger inserted with V-baffle at the center of the tube. Jedsadaratanachai et al. [24] reported the flow and heat transfer mechanisms in a tube heat exchanger with $\mathrm{V}$-shaped baffle placed on the tube wall. As shown in the figures, the $\mathrm{V}$-Upstream wavy surface gives the highest on both heat transfer rate and pressure loss. The V-Upstream wavy surface performs the nearly value of TEF with V-Upstream baffle [24]. 


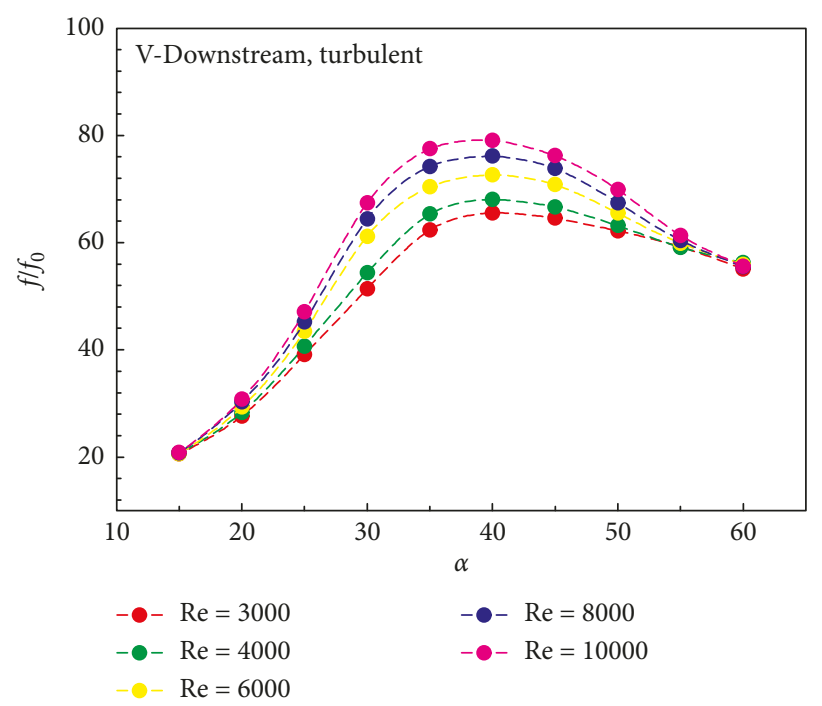

(a)

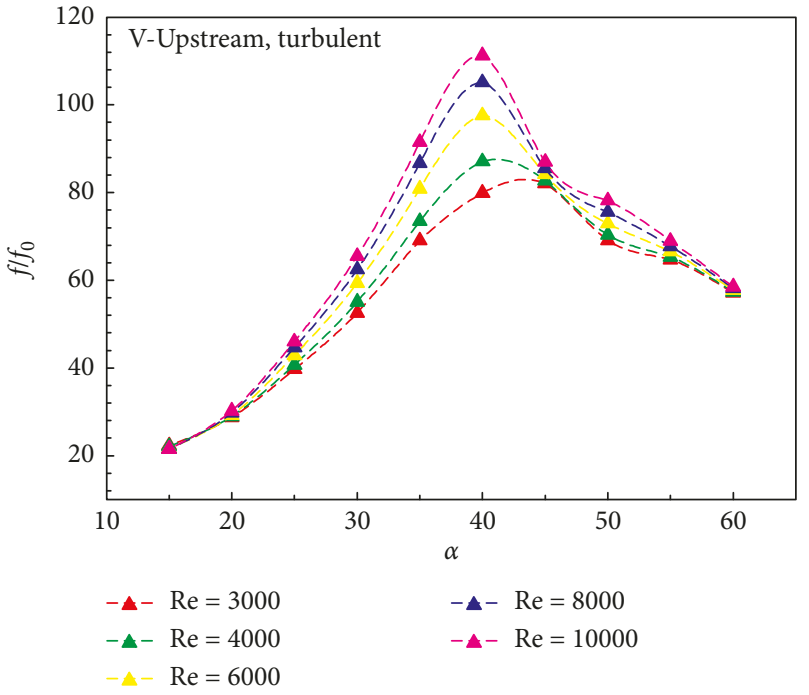

(b)

FIgURE 25: Relations of $f / f_{0}$ with $\alpha$ for the heat exchanger tube inserted with the V-wavy surface for (a) V-Downstream and (b) V-Upstream at the turbulent regime.

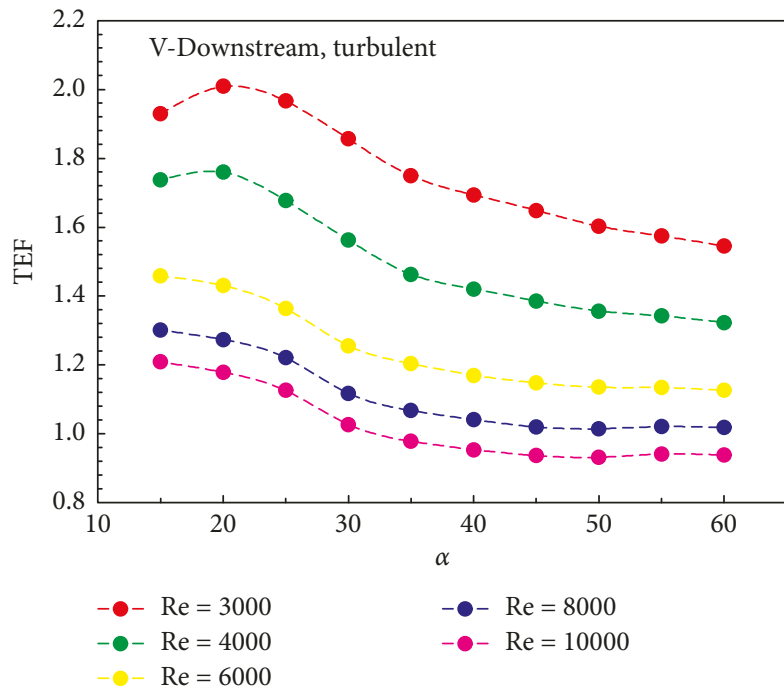

(a)

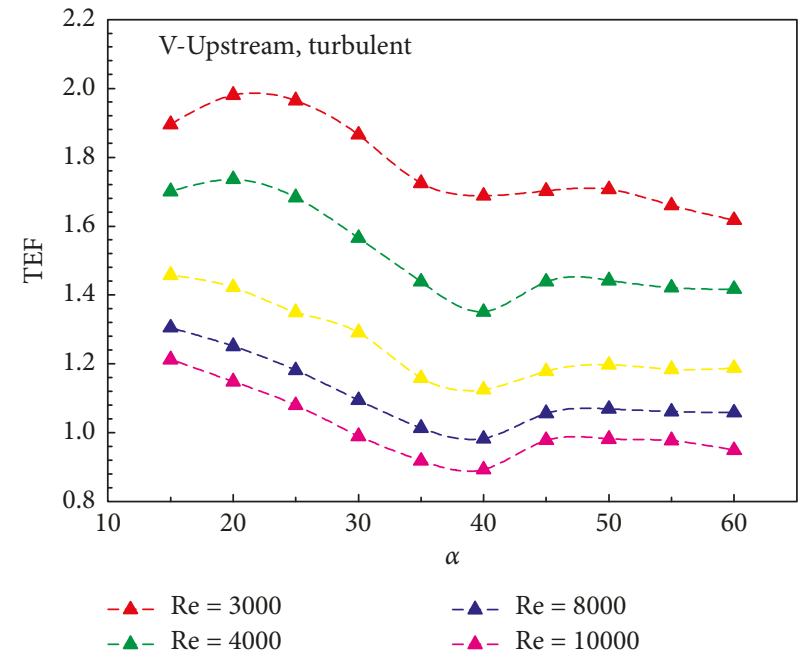

(b)

Figure 26: Relations of the TEF with $\alpha$ for the heat exchanger tube inserted with the V-wavy surface for (a) V-Downstream and (b) VUpstream at the turbulent regime.

\section{Conclusion}

The investigations on flow and heat transfer characteristics in the circular tube heat exchanger inserted with the V-wavy surface are investigated numerically in three dimensions. The laminar and turbulent flows with $\mathrm{Re}=100-1200$ and $\mathrm{Re}=$ 3000-10000, respectively, are considered for the present study. The effects of the flow attack angles and flow directions for the $\mathrm{V}$-wavy surface on flow configuration and heat transfer characteristic are performed. In accordance with the numerical results, the major findings can be concluded as follows.
The V-wavy surface can generate the vortex flow that disturbs the thermal boundary layer on the heat transfer surface. The thermal boundary layer disturbance is the cause for heat transfer and thermal performance improvements in the heat exchanger tube.

The optimum flow attack angle for laminar flow is $30^{\circ}$ and $40^{\circ}$ for $\mathrm{V}$-Downstream and V-Upstream wavy surface, respectively, when considered at TEF. For the turbulent regime, the greatest flow attack angle for the $\mathrm{V}$-wavy surface, which gives the highest TEF, is $20^{\circ}$ for both arrangements. 


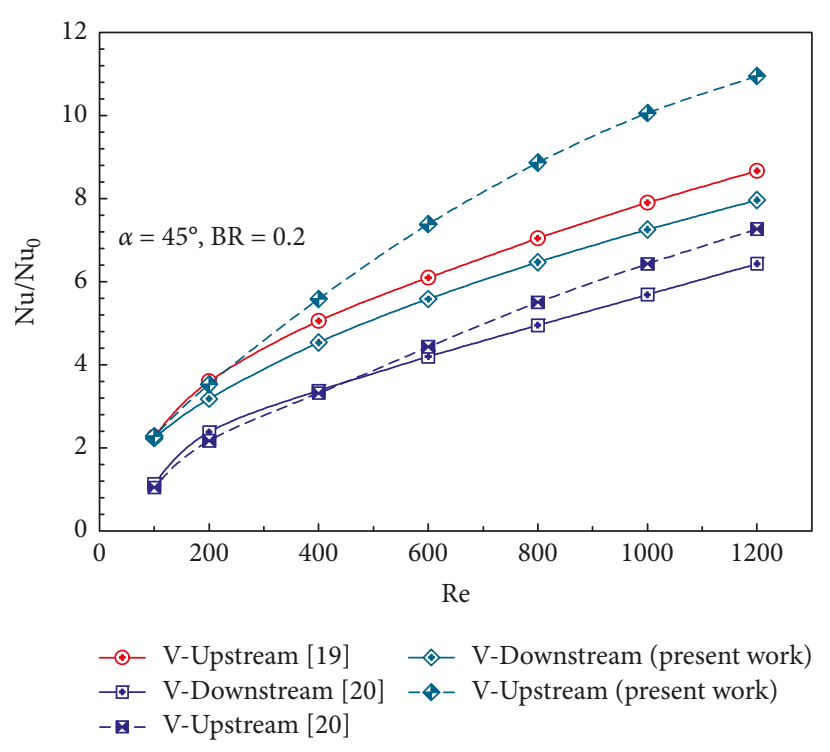

(a)

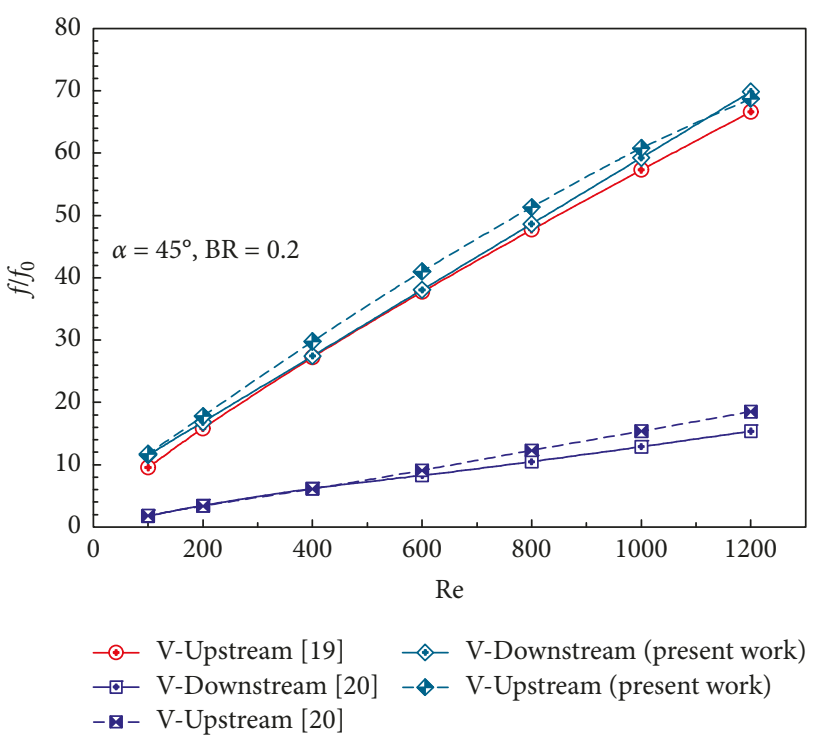

(b)

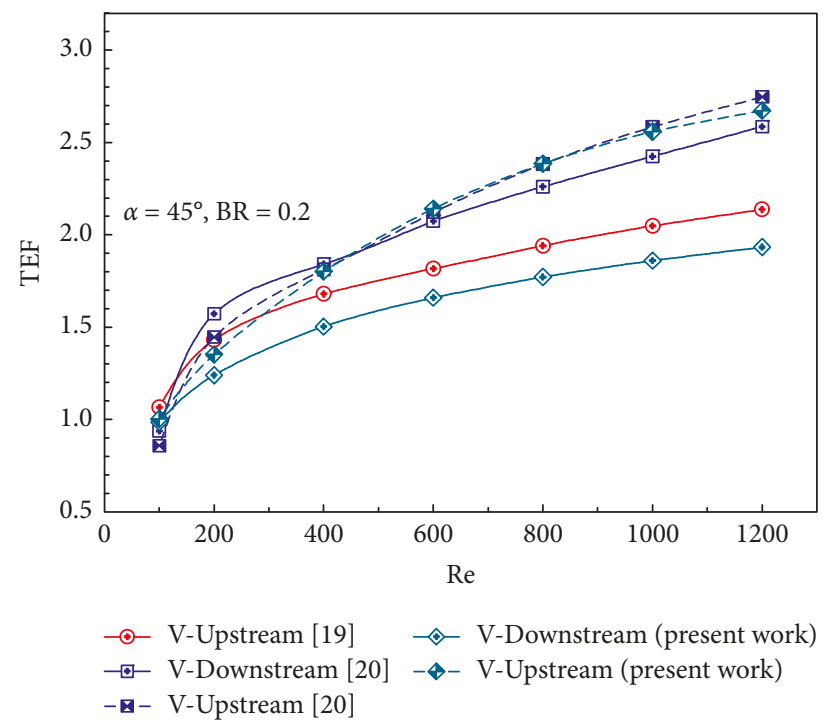

(c)

Figure 27: Comparison with the previous works for (a) $\mathrm{Nu} / \mathrm{Nu}_{0}$ vs $\mathrm{Re}$, (b) $f / f_{0}$ vs $\mathrm{Re}$, and (c) TEF vs Re.

\section{Nomenclature}

$D: \quad$ Tube diameter

$f$ : Friction factor

$h$ : $\quad$ Convective heat transfer coefficient, $\mathrm{W} \mathrm{m}^{-2} \mathrm{~K}^{-1}$

$k$ : Thermal conductivity, $\mathrm{W} \mathrm{m}^{-1} \mathrm{~K}^{-1}$

$\mathrm{Nu}$ : Nusselt number $(=\mathrm{hD} / \mathrm{k})$

p: $\quad$ Static pressure, $\mathrm{Pa}$

Pr: $\quad$ Prandtl number $(\mathrm{Pr}=0.707)$

Re: $\quad$ Reynolds number $(=\rho \bar{u} D / \mu)$

$\mathrm{T}$ : $\quad$ Temperature, $\mathrm{K}$

$u_{\mathrm{i}}$ : $\quad$ Velocity in $X$ direction, $\mathrm{m} \mathrm{s}^{-1}$

$\bar{u}$ : $\quad$ Mean velocity in the channel, $\mathrm{m} \mathrm{s}^{-1}$

$\alpha$ : Angle of attack, degree

TEF: Thermal enhancement factor $\left(=\left(\mathrm{Nu} / \mathrm{Nu}_{0}\right) /\left(f / f_{0}\right)^{1 / 3}\right)$ $\rho: \quad$ Density, $\mathrm{kg} \mathrm{m}^{-3}$

in: Inlet

0: $\quad$ Smooth tube

pp: Pumping power.

\section{Data Availability}

The data used to support the findings of this study are available from the corresponding author upon request.

\section{Conflicts of Interest}

The authors declare that there are no conflicts of interest regarding the publication of this article. 


\section{Acknowledgments}

The authors would like to acknowledge Assoc. Prof. Dr. Pongjet Promvonge for suggestions. The funding of this work is supported by King Mongkut's Institute of Technology Ladkrabang research funds (Contract no. KREF046006).

\section{References}

[1] L. Chen, R. G. A. Brakmann, B. Weigand, J. Rodriguez, M. Crawford, and R. Poser, "Experimental and numerical heat transfer investigation of an impingement jet array with V-ribs on the target plate and on the impingement plate," International Journal of Heat and Fluid Flow, vol. 68, pp. 126-138, 2017.

[2] D. Jin, J. Zuo, S. Quan, S. Xu, and H. Gao, "Thermohydraulic performance of solar air heater with staggered multiple V-shaped ribs on the absorber plate," Energy, vol. 127, pp. $68-77,2017$.

[3] N. S. Deo, S. Chander, and J. S. Saini, "Performance analysis of solar air heater duct roughened with multi gap V-down ribs combined with staggered ribs," Renewable Energy, vol. 91, pp. 484-500, 2016.

[4] A. Kumar and M. H. Kim, "Effect of roughness width ratios in discrete multi V-rib with staggered rib roughness on overall thermal performance of solar air channel," Solar Energy, vol. 119, pp. 399-414, 2015.

[5] R. Maithani and J. S. Saini, "Heat transfer and friction factor correlations for a solar air heater duct roughened artificially with V-ribs with symmetrical gaps," Experimental Thermal and Fluid Science, vol. 70, pp. 220-227, 2016.

[6] A. Kumar and M. H. Kim, "Heat transfer and fluid flow characteristics in air duct with various V-pattern rib roughness on the heated plate: a comparative study," Energy, vol. 103, pp. 75-85, 2016.

[7] X. Fang, Z. Yang, B. C. Wang, M. F. Tachie, and D. J. Bergstrom, "Highly-disturbed turbulent flow in a square channel with V-shaped ribs on one wall," International Journal of Heat and Fluid Flow, vol. 56, pp. 182-197, 2015.

[8] P. Promthaisong, P. Eiamsa-ard, W. Jedsadaratanachai, and S. Eiamsa-ard, "Turbulent heat transfer and pressure loss in a square channel with discrete broken V-rib turbulators," Journal of Hydrodynamics, Ser. B, vol. 28, no. 2, pp. 275-283, 2016.

[9] D. Jin, M. Zhang, P. Wang, and S. Xu, "Numerical investigation of heat transfer and fluid flow in a solar air heater duct with multi V-shaped ribs on the absorber plate," Energy, vol. 89, pp. 178-190, 2015.

[10] S. Abraham and R. P. Vedula, "Heat transfer and pressure drop measurements in a square cross-section converging channel with V and W rib turbulators," Experimental Thermal and Fluid Science, vol. 70, pp. 208-219, 2016.

[11] R. K. Ravi and R. P. Saini, "Nusselt number and friction factor correlations for forced convective type counter flow solar air heater having discrete multi $\mathrm{V}$ shaped and staggered rib roughness on both sides of the absorber plate," Applied Thermal Engineering, vol. 129, pp. 735-746, 2018.

[12] G. Lu, J. Zhao, L. Lin, X. D. Wang, and W. M. Yan, "A new scheme for reducing pressure drop and thermal resistance simultaneously in micro channel heat sinks with wavy porous fins," International Journal of Heat and Mass Transfer, vol. 111, pp. 1071-1078, 2017.

[13] C. Ranganayakulu, X. Luo, and S. Kabelac, "The single-blow transient testing technique for offset and wavy fins of compact plate-fin heat exchangers," Applied Thermal Engineering, vol. 111, pp. 1588-1595, 2017.

[14] M. Khoshvaght-Aliabadi, A. Jafari, O. Sartipzadeh, and M. Salami, "Thermal-hydraulic performance of wavy plate-fin heat exchanger using passive techniques: perforations, winglets, and nanofluids," International Communications in Heat and Mass Transfer, vol. 78, pp. 231-240, 2016.

[15] F. Duan, K. W. Song, H. R. Li, L. M. Chang, Y. H. Zhang, and L. B. Wang, "Numerical study of laminar flow and heat transfer characteristics in the fin side of the intermittent wavy finned flat tube heat exchanger," Applied Thermal Engineering, vol. 103, pp. 112-127, 2016.

[16] L. Xiao, T. Wu, S. Feng, X. Du, and L. Yang, "Experimental study on heat transfer enhancement of wavy finned flat tubes by water spray cooling," International Journal of Heat and Mass Transfer, vol. 110, pp. 383-392, 2017.

[17] B. Lotfi, B. Sundén, and Q. Wang, "An investigation of the thermo-hydraulic performance of the smooth wavy fin-andelliptical tube heat exchangers utilizing new type vortex generators," Applied Energy, vol. 162, pp. 1282-1302, 2016.

[18] C. Xu, L. Yang, L. Li, and X. Du, "Experimental study on heat transfer performance improvement of wavy finned flat tube," Applied Thermal Engineering, vol. 85, pp. 80-88, 2015.

[19] A. Boonloi and W. Jedsadaratanachai, "Laminar forced convection and heat transfer characteristics in a square channel equipped with V-wavy surface," Journal of Mathematics and Statistics, vol. 13, no. 3, pp. 251-260, 2017.

[20] A. Boonloi and W. Jedsadaratanachai, "Effect of flow attack angle for $\mathrm{V}$-wavy plate on flow and heat transfer in a square channel heat exchanger," Journal of Engineering, vol. 2018, Article ID 9487070, 10 pages, 2018.

[21] W. Jedsadaratanachai and A. Boonloi, "Influences of the wavy surface inserted in the middle of a circular tube heat exchanger on thermal performance," Journal of Mechanical Science and Technology, vol. 29, no. 9, pp. 4031-4046, 2015.

[22] W. Jedsadaratanachai and A. Boonloi, "Performance analysis and flow visualization in a round tube heat exchanger inserted with wavy V-ribs," Advances in Mechanical Engineering, vol. 9, no. 9, pp. 1-16, 2017.

[23] W. Jedsadaratanachai and N. Jayranaiwachira, "Effect of pitch to height ratio on flow visualization, heat transfer, and thermal performance in a round tube with upstream RWVG," Advances in Mechanical Engineering, vol. 6, Article ID 471720, 2014.

[24] W. Jedsadaratanachai, N. Jayranaiwachira, and P. Promvonge, "3D numerical study on flow structure and heat transfer in a circular tube with V-baffles," Chinese Journal of Chemical Engineering, vol. 23, pp. 342-349, 2015. 


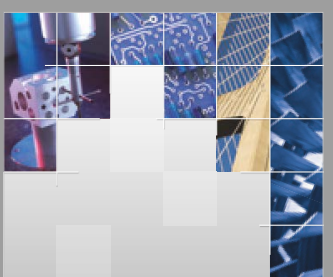

\section{Enfincering}
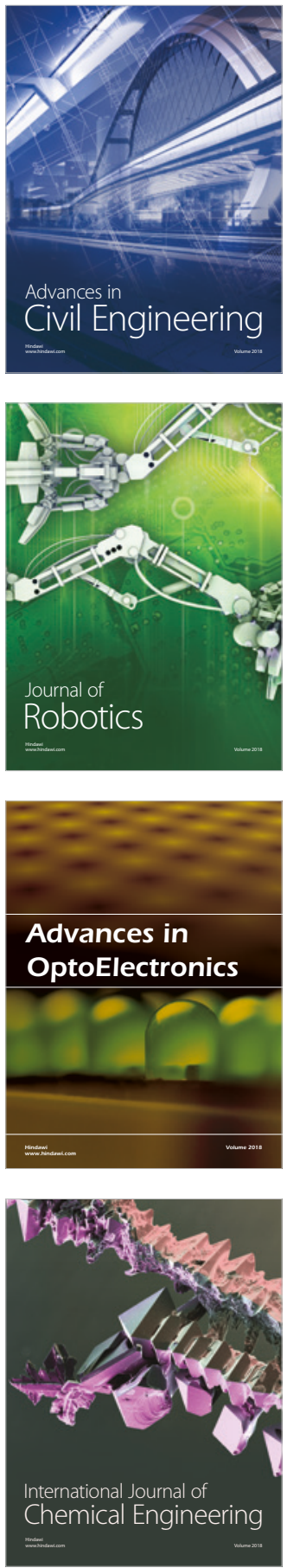

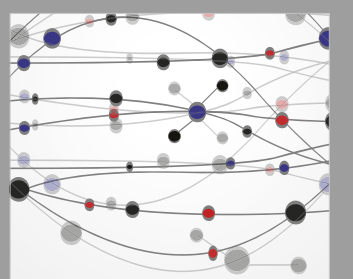

\section{Rotating \\ Machinery}

The Scientific World Journal

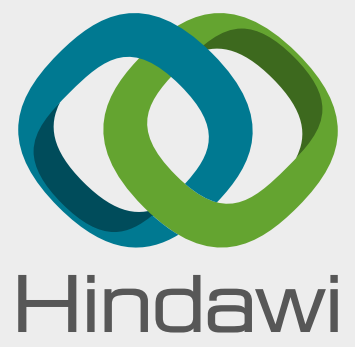

Submit your manuscripts at

www.hindawi.com
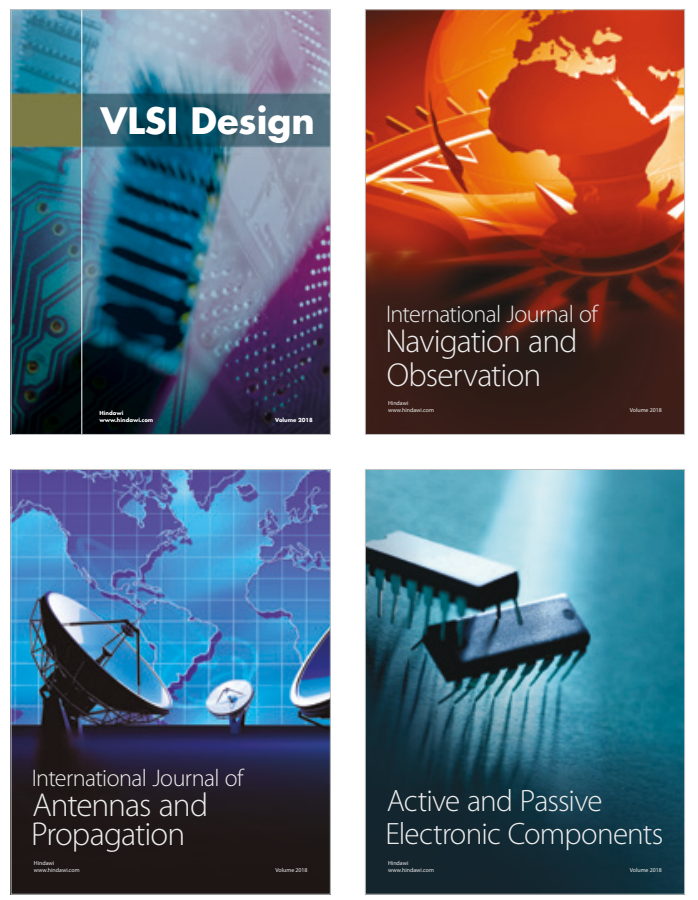
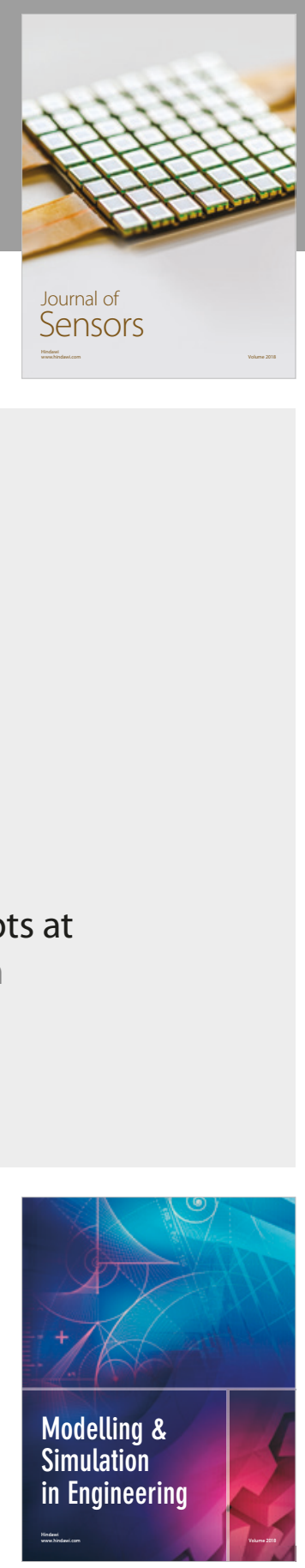

\section{Advances \\ Multimedia}
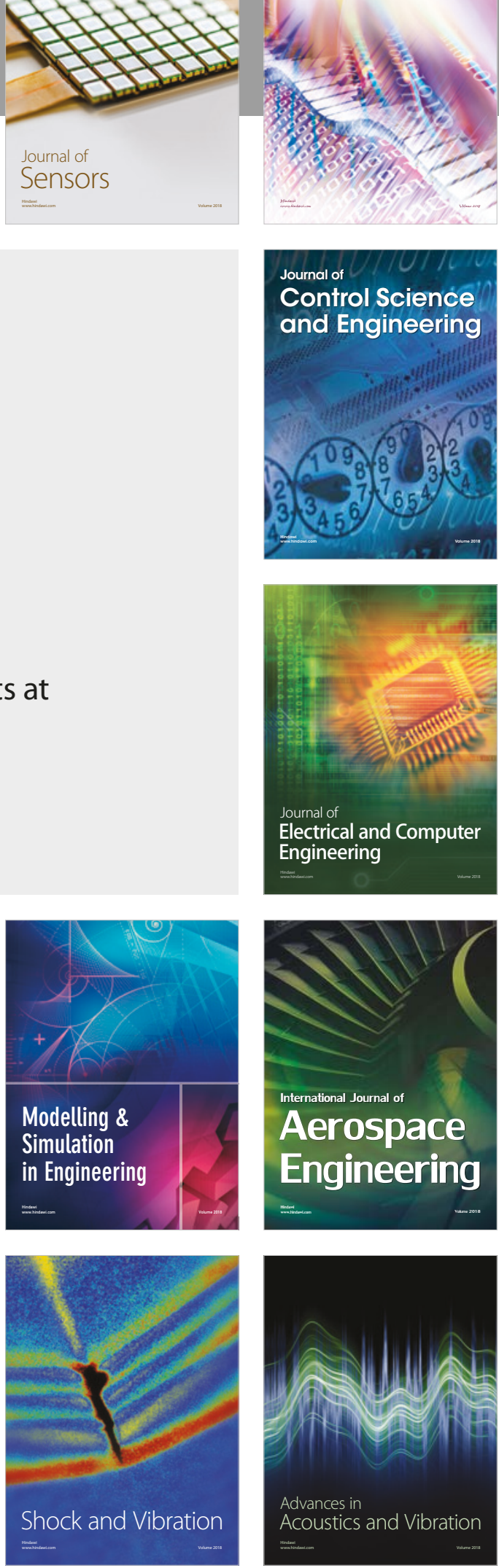